\title{
Effects of MDPV on dopamine transporter regulation in male rats. Comparison with cocaine.
}

Raul Lopez-Arnau, Leticia Duart-Castells, Barbara Aster, Jorge Camarasa, Elena

Escubedo $^{1}$, David Pubill $^{1 凶}$

Department of Pharmacology, Toxicology and Therapeutic Chemistry, Pharmacology

Section and Institute of Biomedicine (IBUB), Faculty of Pharmacy, University of

Barcelona, Barcelona, Spain.

${ }^{1}$ Contributed equally to this work

\section{Corresponding author:}

${ }^{\square}$ David Pubill, Department of Pharmacology, Toxicology and Therapeutic Chemistry, Faculty of Pharmacy, University of Barcelona. Av. Joan XXIII, 27-31, 08028,

Barcelona, Spain.

Email: $\underline{\text { d.pubill@ub.edu }}$

Tel: +34-934024531 Fax: +34-934035982

\section{Acknowledgments}

This study was supported by grants from Ministerio de Economia y Competitividad (grant SAF2016-75347R) and Plan Nacional sobre Drogas \#2014I020, \#2016I004). LDC received FPU grants from the Ministerio de Economía y Competitividad (15/02492). JC, LDC, EE, RLA and DP belong to the quality mentioned group 2017SGR979 by Generalitat de Catalunya. RLA position was funded by an institutional program of the Universitat de Barcelona in collaboration with Obra Social de la Fundació Bancària La Caixa.

We are grateful to Dr. Anthony L. Riley for helpful critical reading of the manuscript. We also acknowledge Nacho Fargas for eventual technical support.

\section{Conflict of interest}

On behalf of all authors, the corresponding author states that there is no conflict of interest. 


\begin{abstract}
Rationale

MDPV (3,4-methylenedioxypyrovalerone) is a synthetic cathinone present in bath salts. It is powerful psychostimulant and blocker of the dopamine transporter (DAT), like cocaine. It is known that acute exposure to psychostimulants induces rapid changes in DAT function.

Objectives
\end{abstract}

To investigate the effects of MDPV on DAT function comparing with cocaine . Methods

Binding of $\left[{ }^{3} \mathrm{H}\right]$ WIN 35428 was performed on PC 12 cells treated with MDPV and washed. Rat striatal synaptosomes were incubated with MDPV or cocaine $(1 \mu \mathrm{M})$ for 1 $\mathrm{h}$ and $\left[{ }^{3} \mathrm{H}\right]$ dopamine (DA) uptake was performed. Also, different treatments with MDPV or cocaine were performed in Sprague-Dawley rats to assess locomotor activity and ex vivo $\left[{ }^{3} \mathrm{H}\right] \mathrm{DA}$ uptake.

Results

MDPV increased surface $\left[{ }^{3} \mathrm{H}\right]$ WIN 35428 binding on PC 12 cells. In vitro incubation of synaptosomes with MDPV produced significant increases in $\mathrm{V}_{\max }$ and $\mathrm{K}_{\mathrm{M}}$ for $\left[{ }^{3} \mathrm{H}\right] \mathrm{DA}$ uptake. In synaptosomes from MDPV- (1.5 mg/kg, s.c.) and cocaine- (30 mg/kg, i.p.) treated rats there was a significantly higher and more persistent increase in $\left[{ }^{3} \mathrm{H}\right] \mathrm{DA}$ uptake in the case of MDPV than cocaine. Repeated doses of MDPV developed tolerance to this DAT upregulation and $24 \mathrm{~h}$ after the 5-day treatment with MDPV, $\left[{ }^{3} \mathrm{H}\right] \mathrm{DA}$ uptake was reduced. However, a challenge with the same drugs after withdrawal recovered the DAT up-regulation by both drugs and showed an increased response to MDPV vs the first dose. At the same time, animals were sensitized to the stereotypies induced by both psychostimulants.

\title{
Conclusions
}

MDPV induces a rapid and reversible functional up-regulation of DAT more powerfully and lasting than cocaine. 
Keywords: bath salts, cathinones, cocaine, dopamine transporter, dopamine uptake, MDPV, up-regulation.

\section{Introduction}

Membrane neurotransmitter transporters play a key role in the regulation of neural transmission as they are responsible for removal of neurotransmitters released into the synaptic cleft upon neuronal stimulation. Thus, the dopamine transporter (DAT) is crucial for dopaminergic transmission in the nigrostriatal and mesocorticolimbic dopaminergic pathways (see Lohr et al. 2017 or Torres et al. 2013 as reviews) and modifications in its density or transport rate can reduce or enhance the effects of a given amount of dopamine (DA).

DAT, as other monoamine transporters, exhibits a great ability to modify its density in the plasma membrane through a very fast trafficking through internalization and recycling in a protein kinase C (PKC)-regulated manner (Loder and Melikian 2003; Ramamoorthy et al. 2011; Schmitt and Reith 2010).

Psychostimulants increase synaptic monoamine levels by acting on their transporters, either by directly binding and inhibiting their function (e.g., cocaine, Ritz et al. 1987) or through a combined mechanism consisting in entering the cell as a transporter substrate and reversing the transport of cytosolic monoamines (e.g., amphetamine) which are previously displaced from synaptic vesicles by the drug (Sulzer and Galli 2003).

Apart from these acute effects on monoamine uptake, rapid and reversible compensatory changes in transporters and their function have been reported as well. . Generally speaking, using samples from which residual drug has been washed away, psychostimulants that act as substrates of the transporters (e.g., amphetamine and analogues) induce an acute decrease in uptake, whereas blockers (e.g., cocaine or methylphenidate) tend to increase it. For example, an acute injection of methamphetamine (METH) to rats reversibly decreases plasmalemmal DA uptake in striatal synaptosomes (Fleckenstein et al. 1997). Similarly, uptake of serotonin is affected by METH treatment (Haughey et al. 2000). Moreover, in vitro incubation of striatal synaptosomes with METH followed by drug washout, rapidly decreased DAT activity, but not total WIN 35428 binding sites (Escubedo et al. 2005; Pubill et al. 2005; Sandoval et al. 2001). Similar effects were reported for MDMA (3,4methylenedioxymethamphetamine) (Chipana et al. 2006; Hansen et al. 2002). It has 
been reported that PKC-mediated DAT phosphorylation contributes to this in vitro 2001) which is accompanied by transporter internalization (Saunders et al. 2000; Johnson et al. 2005).

Regarding cocaine, published results from animal in vivo and human post-mortem studies are variable depending on the subjects and experimental design. Most reports demonstrate that chronic exposure to cocaine increases DAT binding sites and function (Little et al. 1999; Mash et al. 2002; Staley et al. 1994), but others show a decrease or no change in the striatum following cocaine exposure (i.e Farfel et al. 1992; Izenwasser and Cox 1990; Letchworth et al. 1997; Peraile et al. 2010; Samuvel et al. 2008; Wilson et al. 1994). However, in vitro studies in hDAT-transfected cells generally report that acute cocaine treatment produces increases in surface $\left[{ }^{3} \mathrm{H}\right]$ WIN 35428 binding and $\left[{ }^{3} \mathrm{H}\right] \mathrm{DA}$ uptake, with no change in DAT total protein or mRNA, but through induction of the trafficking from endosomes to the plasma membrane by a mechanism that remains to be elucidated (Little et al. 2002; Zahniser and Sorkin 2009).

Synthetic cathinones have become a very popular group of illicit psychostimulants as substitutes of other amphetamine derivatives such as methamphetamine or MDMA (Drug Facts 2018: https://www.drugabuse.gov/publications/drugfacts/syntheticcathinones-bath-salts). One such synthetic cathinone, MDPV (3,4methylenedioxypyrovalerone), shares pharmacodynamics with cocaine. It is a common ingredient of the so-called bath salts (Zuba and Byrska 2013; Johnson and Johnson 2014), which are commercialized by certain Internet sites, although it is currently banned in many countries because its consumption has led to several life-threatening medical consequences (Kesha et al. 2013; Wright et al. 2013). It is a highly selective and potent reuptake inhibitor at monoamine transporters, with greater specificity for the DAT and norepinephrine transporters, compared to that for serotonin transporters. In vitro experiments have shown that MDPV is a more potent reuptake inhibitor than cocaine at DAT (Baumann et al. 2013; Cameron et al. 2013; Simmler et al. 2013), while in vivo studies have found that MDPV has is at least 10-fold more potent at increasing extracellular DA than cocaine (Baumann et al. 2013). Moreover, MDPV robustly increases locomotion, traveled distance and stereotypic movements in rats and mice and produces more intense locomotor and rewarding effects compared to cocaine (Aarde et al. 2013; Gatch et al. 2013; Lopez-Arnau et al. 2017). 
Considering the persistence of synthetic cathinone abuse, especially MDPV (Alvarez et neuropharmacological profile to better understand the effects and risks of this drug. To our knowledge, there are no previous reports of the effects of MDPV or any other synthetic cathinone on DAT regulation. Therefore, the aim of this work is to investigate the effects of MDPV on DAT density and function, using in vitro (PC12 cells and striatal synaptosomes) and ex vivo models (striatal synaptosomes from treated rats) after an acute exposure to the drug and a sensitization regime. Parallel experiments with cocaine were also run in order to compare their effects

\section{Materials and methods}

\section{Drugs and reagents}

MDPV was synthesized in racemic form as hydrochloride in our laboratory as described previously (Novellas et al. 2015) and with permission from the University of Barcelona. Cocaine-HCl was provided by the Spanish National Institute of Toxicology. MDPV and cocaine solutions for injection were freshly prepared in saline $(0.9 \% \mathrm{NaCl}, \mathrm{pH}=7.4)$ every day before administration.

$\left[{ }^{3} \mathrm{H}\right] \mathrm{DA}$ and $\left[{ }^{3} \mathrm{H}\right]$ WIN 35428 were from PerkinElmer (Boston, MA, USA). Dulbecco's modified Eagle's medium (DMEM), culture serums and antibiotics were purchased from GIBCO (Invitrogen Corp., Paisley, UK). Pargyline, bupropion, HEPES sodium and ascorbic acid were purchased from Sigma-Aldrich Company Ltd. All other reagents were of analytical grade and obtained from several commercial sources.

\section{PC12 cell culture and treatment}

The rat pheochromocytoma PC 12 cell line has been reported as a model to study DAT trafficking (Loder and Melikian, 2003) and we used it to investigate the effects of amphetamine derivatives on DA transport (Chipana et al., 2008). For these reasons we considered these cells a suitable model for this study. PC 12 cells were routinely cultured in $92 \mathrm{~mm}$ dishes (Nunc) coated with collagen and maintained in DMEM supplemented with heat-inactivated $5 \%$ fetal bovine serum, $10 \%$ horse serum, $10 \mathrm{mM}$ HEPES, $2 \mathrm{mM}$ glutamine, $25 \mathrm{UI} / \mathrm{ml}$ penicillin and $25 \mu \mathrm{g} / \mathrm{ml}$ streptomycin. Cells were cultured to semi-confluency in a humidified $5 \% \mathrm{CO}_{2}$ atmosphere at $37{ }^{\circ} \mathrm{C}$, and medium was changed every 2-3 days. For splitting, cells were dislodged from the dish using a 
pipette with medium, with a portion of these replated onto new culture dishes. Cells were used between passages 15 and 25 .

To ensure their proper differentiation, cells were mechanically dislodged and seeded (200 X $10^{3}$ cells per well) onto collagen-coated 24-well plates (Nunc) in medium containing $50 \mathrm{ng} / \mathrm{ml}$ nerve growth factor (NGF, Upstate Biotechnology, Lake Placid, $\mathrm{NY}), 1 \%$ horse serum, $10 \mathrm{mM}$ HEPES and 2\% glutamine in DMEM. Under these conditions, the cells developed a neuronal phenotype with neurite outgrowth that was already apparent $24 \mathrm{~h}$ after seeding (Garcia-Rates et al. 2007).

Treatments were performed $48 \mathrm{~h}$ after seeding in differentiation medium. MDPV was dissolved in DMEM and added to the corresponding wells in a volume of $10 \mu \mathrm{l}$ to reach the desired final concentration. The concentration of MDPV used $(0.1 \mu \mathrm{M})$ was chosen from preliminary experiments showing that higher concentrations required many washes to be removed, thus compromising the attachment of the cells. Previous reports stated that MDPV can reach peak concentrations of around 1 and $4 \mu \mathrm{M}$ in plasma and striatum, respectively, after subcutaneous administration (Novellas et al. 2015). Control wells received $10 \mu \mathrm{l}$ of DMEM. The plates were returned to the incubator for the desired time, until the binding experiment were performed.

\section{Binding of $\left[{ }^{3}\right.$ H]WIN 35428 to PC12 cells}

$\left[{ }^{3} \mathrm{H}\right]$ WIN 35428 binding was used to label membrane DAT in differentiated PC 12 cells. After incubation with MDPV, the medium was carefully removed and the cells were washed twice with $1 \mathrm{ml}$ of warm Dulbecco's phosphate buffered saline (PBS, Biological Industries Inc.). Then, $500 \mu 1$ of $\left[{ }^{3} \mathrm{H}\right]$ WIN35428 (final radioligand concentration: $5 \mathrm{nM}$ ) diluted in $0.32 \mathrm{M}$ sucrose-supplemented PBS was added to each well. A parallel set of wells also contained $30 \mu \mathrm{M}$ bupropion to assess non-specific binding. The plates were placed on ice, and incubation was performed for $2 \mathrm{~h}$ at $4^{\circ} \mathrm{C}$. Binding was terminated by detaching the cells by pipetting and filtering through Whatman GF/B glass-fiber filters pre-soaked in $0.5 \%$ polyethileneimine, followed by three $1 \mathrm{ml}$ washes of wells and filters with ice-cold buffer. The radioactivity retained in the filters was measured through liquid scintillation spectrometry. Each experiment was run in triplicate wells. 


\section{Animals and treatment}

The experimental protocols concerning the use of animals in this work were approved by the Animal Ethics Committee of the University of Barcelona under supervision of the Autonomous Government of Catalonia, following the guidelines of the European Communities Council (86/609/EEC). Efforts were made to minimize suffering and reduce the number of animals used.

Male adult Sprague-Dawley (SD) rats (aged 10-12 weeks and weighing 250-350 g; Harlan Ibérica, Barcelona, Spain) were used for synaptosome assays. They were housed at $22{ }^{\circ} \mathrm{C}$ under a 12 -h light/dark cycle with free access to food and water. For in vitro incubations with the drugs, animals ( 2 rats per experiment) were anesthetized and sacrificed and synaptosomes were obtained. For ex-vivo experiments with synaptosomes originating from treated animals, MDPV $(1.5 \mathrm{mg} / \mathrm{kg})$ and cocaine $(30 \mathrm{mg} / \mathrm{kg})$ were dissolved in saline and administered subcunateously (s.c.) or intraperitoneally (i.p.), respectively in a volume of $1 \mathrm{ml} / \mathrm{kg}$. Then, the animals were anesthetized and sacrificed and synaptosomes were obtained after 1, 3 or $16 \mathrm{~h}$. The dose of MDPV used in this study $(1.5 \mathrm{mg} / \mathrm{kg}$ ) is equivalent to a dose of approximately $15 \mathrm{mg}$ in humans (ReaganShaw et al. 2008; Novellas et al. 2015) which is in the middle range of the doses most commonly used by consumers. The dose of cocaine of $30 \mathrm{mg} / \mathrm{kg}$ has been chosen on the basis that MDPV is more potent (10-30-fold) than cocaine (Baumann et al. 2013; Kolanos et al. 2013; Simmler et al. 2013), and the psychomotor stimulation induced by $30 \mathrm{mg} / \mathrm{kg}$ of cocaine was not statistically different from that induced by $1.5 \mathrm{mg} / \mathrm{kg}$ of MDPV (see Figs. 6 and 7).

The repeated administration procedure consisted in a daily administration of saline, MDPV or cocaine for 5 consecutive days, followed by 10 days of withdrawal and, one day after, a challenge of saline $(1 \mathrm{~m} / \mathrm{kg})$, MDPV $(1.5 \mathrm{mg} / \mathrm{kg}$, s.c. $)$ or cocaine $(30 \mathrm{mg} / \mathrm{kg}$, i.p.) was injected. A similar procedure was reported by Gregg et al (2013) and our group, producing a robust psychomotor sensitization to MDPV and cocaine in mice (Buenrostro-Jáuregui et al., 2016). One set of animals received only the first dose to obtain the uptake values $1 \mathrm{~h}$ after the acute dose (Day $1, n=4$ for each treatment). Two other sets of rats were sacrificed 1 and $24 \mathrm{~h}$ after the fifth dose to obtain the results of Day 5 and Day 6 ( $n=4$ and 6 for each treatment group, respectively). Finally, another set of 6 animals per group was sacrificed $1 \mathrm{~h}$ after the challenge. 


\section{Obtention of striatal synaptosomes}

Striatal synaptosomes (P2 fraction) were obtained as described by Sandoval et al. (2001), with minor modifications. Rats were decapitated under isoflurane anesthesia, their brains rapidly removed and the striatum was dissected out on ice, weighed and placed in 20 volumes of cold homogenization buffer $(5 \mathrm{mM}$ Tris- $\mathrm{HCl}$ and $320 \mathrm{mM}$ sucrose). Tissues were homogenized on ice using a borosilicate glass tube fitted with a motor-driven Teflon pestle and centrifuged twice to obtain the $\mathrm{P} 2$ fraction (synaptosomes). In the case of synaptosomes originating from treated rats, the pellet was resuspended in $5 \mathrm{ml}$ of Tris-sucrose buffer and re-centrifuged 3 times, in order to wash out the residual drugs that could interfere with the experiments.

Finally, the synaptosome fraction was resuspended in Hank's Balanced Salt Solution (HBSS, Biological Industries, Inc.) supplemented with $5.5 \mathrm{mM}$ glucose and $20 \mathrm{mM}$ HEPES-sodium (HBSS/G/H, pH 7.4) for [ $\left.{ }^{3} \mathrm{H}\right] \mathrm{DA}$ uptake experiments or in $0.1 / 0.32 \mathrm{M}$ sodium phosphate/sucrose-buffer ( $\mathrm{pH} 7.9$ ) for $\left[{ }^{3} \mathrm{H}\right]$ WIN 35428 binding. The resuspension was done to reach a final protein concentration of approximately 0.1 $\mathrm{mg} / \mathrm{ml}$. Protein concentration was determined using the BioRad Protein Reagent (BioRad Labs., Inc., Hercules, CA, USA) according to the manufacturer's instructions and using bovine serum albumin as a standard.

\section{$\left[{ }^{3} \mathrm{H}\right] \mathrm{DA}$ uptake}

For in vitro treatment experiments, synaptosomes were obtained as described above and distributed in $1 \mathrm{ml}$ aliquots in centrifuge tubes to perform the incubation with MDPV or cocaine in a shaking water bath at $37^{\circ} \mathrm{C}$ for $1 \mathrm{~h} .10 \mu \mathrm{l}$ of MDPV or cocaine solution or buffer was added to each tube to reach the desired final concentration $(1 \mu \mathrm{M})$. After incubation, synaptosomes were centrifuged at $13000 \mathrm{x}$ g for $20 \mathrm{~min}$ and washed three more times with $5 \mathrm{ml}$ of Tris-sucrose buffer followed by centrifugation. The final pellets were resuspended in uptake buffer (HBSS/G/H buffer plus $10 \mu \mathrm{M}$ pargyline and $1 \mathrm{mM}$ ascorbic acid). For experiments with tissue from treated rats, striatal synaptosomes were obtained as described above and, after the three washes, directly resuspended in uptake buffer.

Reaction tubes consisted in $0.125 \mathrm{ml}$ of uptake buffer, $0.1 \mathrm{ml}$ of synaptosome suspension and $0.025 \mathrm{ml}$ of $\left[{ }^{3} \mathrm{H}\right] \mathrm{DA}$ added at the start of incubation. The remaining synaptosomes from each pellet were kept for further protein concentration assessment. 
Tubes were warmed 5 min at $37^{\circ} \mathrm{C}$ before the addition of $\left[{ }^{3} \mathrm{H}\right] \mathrm{DA}$ after which filtration as described for binding experiments. The radioactivity trapped on the filters was measured by liquid scintillation spectrometry. Non-specific uptake was determined at $4{ }^{\circ} \mathrm{C}$ in parallel samples containing $100 \mu \mathrm{M}$ cocaine. Specific DA uptake was calculated subtracting non-specific uptake values from those of total uptake $\left(37^{\circ} \mathrm{C}\right)$. Each experiment was run in duplicate tubes.

Specific DA uptake for each condition was normalized by dividing by the protein concentration and expressed as percentage of uptake with respect to control tubes.

We could not perform reliable $\left[{ }^{3} \mathrm{H}\right] \mathrm{DA}$ uptake in differentiated PC 12 cells with our means due to methodological issues (i.e., the need to perform repeated washes to remove free $\left[{ }^{3} \mathrm{H}\right] \mathrm{DA}$, leading to cell loss by detachment or, alternatively, to mechanically detach the cells and filtering which provokes indeterminate neurite and cell breaking with substrate leakage).

\section{Locomotor activity recording}

The locomotor responses induced by MDPV (1.5 mg/kg, s.c.) or cocaine (30 mg/kg, i.p.) were assessed in black Plexiglas open field arenas ( $1 \times$ w x h: $45 \times 45 \times 40 \mathrm{~cm})$ under low-light conditions. Two days before testing, the animals were handled for 10 $\min$, administered saline $(1 \mathrm{ml} / \mathrm{kg})$ and placed in the arena for habituation for $30 \mathrm{~min}$ each day. On the test day, the rats were administered the assigned treatment and placed in the arenas and their horizontal travelling were video-monitored by a zenithal videocamera coupled to a computer running a tracking software (Smart 3.0, Panlab, S.L.U., Barcelona, Spain) for $60 \mathrm{~min}$. Total travelled distances were obtained and analyzed.

\section{Stereotypy scoring}

Stereotyped behaviors were scored by two observers blind to treatment condition using the method of Creese and Iversen (1974). Briefly, video recordings (60 min) were divided into 10-min segments. Behavior during the first min of each segment was rated on a $0-6$ scale: $0=$ asleep or lying down, $1=$ predominantly slow locomotor activity with non-stereotyped rearing and sniffing, 2 = predominantly rapid locomotor activity with bursts of stereotyped rearing and sniffing, 3 = predominantly stereotyped rearing and sniffing with some locomotor activity, $4=$ stereotyped rearing and sniffing 
maintained in a small area of the enclosure, $5=$ stereotyped behavior maintained in a small area with oral stereotypies (licking or gnawing), $6=$ assumption of awkward or bizarre posture. A score between 0 and 2 is, generally, considered a normal behavior. Both raters were trained on the same set of sample videos and achieved an inter-rater reliability of at least 0.90 before scoring experimental recordings. The score for each rat and experimental day is the average sum of the scores obtained in each recording block by both observers.

\section{Data analysis}

One-way ANOVA followed by Tukey's post-hoc test or Student's t test was used to analyze data from the binding experiments with cells and synaptosomes. Paired data were applied when comparing $\mathrm{K}_{\mathrm{M}}$ and $\mathrm{V}_{\max }$ of control and MDPV from different experiments, as each one was performed with the same synaptosomal preparation. A two-way ANOVA was used to compare the effects of MDPV, cocaine and saline on DA uptake (treatment $\mathrm{x}$ time factors), as well as to compare the effects of the first dose with those of the challenge (treatment $x$ dose factors) in the sensitization schedule. Finally, a two-way (day and treatment) ANOVA with repeated measures was used to analyze the temporal evolution of locomotion and stereotypies during the sensitization procedure. When the overall ANOVA yielded significant effects, Tukey's post-hoc tests were applied for comparisons between groups.

\section{Results}

\section{MDPV treatment increases $\left[{ }^{3} \mathrm{H}\right]$ WIN 35428 binding on the surface of differentiated PC12 cells}

After preliminary trials, we assessed the effect of the exposure to $0.1 \mu \mathrm{M}$ MDPV on $\left[{ }^{3} \mathrm{H}\right]$ WIN 35428 binding to intact NGF-differentiated PC12 cells, as a measure of DAT present in the cell membrane. Incubation with the cathinone was performed for $30 \mathrm{~min}$, 1, 3 and $24 \mathrm{~h}$. As can be seen in Fig. 1, a short (30 min-1 h) exposure to MDPV was able to increase superficial DAT expression by $120 \%$ compared to control (DMEM alone). This elevation was also evident at 3 hours, but was no longer different from control at $24 \mathrm{~h}$ (one-way ANOVA: $\mathrm{F}_{6,14}=8,297, \mathrm{p}<0.001$ ). 


\section{In vitro effects of MDPV and cocaine on $\left[{ }^{3} \mathrm{H}\right] \mathrm{DA}$ uptake in striatal synaptosomes}

The effects observed on $\left[{ }^{3} \mathrm{H}\right]$ WIN 35428 binding in differentiated PC12 cells encouraged us to test if this increased binding was accompanied by increased function of DAT (increased DA uptake). Unfortunately, due to technical issues we could not perform uptake assays with these cells (see Methods). For this reason, we chose an alternative experimental model and investigated whether in vitro incubation of striatal synaptosomes with MDPV was able to modify DA uptake, as occurs with other amphetamine derivatives, and how such modification was influenced by substrate concentration. Due to its similar mechanism of action, we also sought to compare these effects with those of cocaine. For this reason, we performed kinetic $\left[{ }^{3} \mathrm{H}\right] \mathrm{DA}$ uptake experiments with synaptosomes pre-incubated with either MDPV or cocaine (both at 1 $\mu \mathrm{M}$ ) for $1 \mathrm{~h}$ and compared the values with those obtained from control (pre-incubated in the absence of drug) synaptosomes.

For MDPV, significant increases in both $\mathrm{K}_{\mathrm{M}}(62 \%)$ and $\mathrm{V}_{\max }(57 \%)$ were obtained, showing higher uptake values in the MDPV group as long the substrate concentration was raised (Fig. 2). Cocaine induced a more modest increase in $\mathrm{V}_{\max }(30 \%)$, without significantly modifying the $K_{M}$ value (Fig. 3).

We also performed experiments measuring $\left[{ }^{3} \mathrm{H}\right] \mathrm{DA}$ uptake after incubating striatal synaptosomes for $1 \mathrm{~h}$ with increasing concentrations of MDPV or cocaine. In this case, we chose a constant $\left[{ }^{3} \mathrm{H}\right] \mathrm{DA}$ concentration of $0.2 \mu \mathrm{M}$ because differences between control and drug-treated kinetic curves were more apparent from and above this concentration. One-way ANOVA for each drug reported statistically significant effects of drug treatment (MDPV: $F_{5,12}=3.667, p<0.05$; cocaine: $\left.F_{5,12}=19.20, p<0.0001\right)$. As depicted in Fig. 4A, MDPV produced a statistically significant increase in uptake at a concentration of $0.1 \mu \mathrm{M}$ whereas the differences in uptake at the rest of concentrations did not reach statistical significance. On the other hand, cocaine started showing a tendency to up-regulate uptake at a concentration of $1 \mu \mathrm{M}$, which became statistically significant at concentrations of 10 and $50 \mu \mathrm{M}$ (Fig 4B).

\section{Administration of a single dose of MDPV up-regulates DA uptake more potently and longer than cocaine.}

After the in vitro results, we investigated whether acute administration of MDPV to rats was able to similarly increase DA uptake. Accordingly, we treated rats with saline, 
MDPV (1.5 mg/kg, s.c.) or cocaine (30 mg/kg, i.p.) and sacrificed them after 1, 3 and 16 h (Fig. 5). Striatal synaptosomes were immediately obtained and washed and uptake of $\left[{ }^{3} \mathrm{H}\right] \mathrm{DA}(0.2 \mu \mathrm{M})$ was performed. This substrate concentration was chosen after the in vitro experiments showing that the differences between groups were more apparent at higher $\left[{ }^{3} \mathrm{H}\right] \mathrm{DA}$ concentrations.

The two-way ANOVA of the results showed the existence of significant differences for treatment $\left(\mathrm{F}_{2,27}=60.09, \mathrm{p}<0.0001\right)$ and time $\left(\mathrm{F}_{2,27}=25.86, \mathrm{P}<0.0001\right)$, as well as a significant interaction between them $\left(\mathrm{F}_{4,27}=13.30, \mathrm{p}<0.0001\right)$. MDPV administration induced a significant increase in $\left[{ }^{3} \mathrm{H}\right] \mathrm{DA}$ uptake (around $120 \%, \mathrm{p}<0.001$ ) measured $1 \mathrm{~h}$ after administration which persisted until $3 \mathrm{~h}$ post-treatment.. Cocaine treatment also induced a significant, but smaller, increase than MDPV in $\left[{ }^{3} \mathrm{H}\right] \mathrm{DA}$ uptake (around 75 $\%, \mathrm{p}<0.001$ ) when assessed $1 \mathrm{~h}$ after administration, but it was no longer evident $3 \mathrm{~h}$ post-treatment.

\section{Effects of a repeated administration of MDPV or cocaine on DA uptake}

In view of the effects of an acute in vivo administration of MDPV $(1.5 \mathrm{mg} / \mathrm{kg})$, we investigated the consequences of its daily administration for 5 days, followed by 10 days of withdrawal, on the changes in DA uptake induced by a challenge with the drug $(1.5 \mathrm{mg} / \mathrm{kg}$, s.c.). One set of rats was sacrificed $1 \mathrm{~h}$ after the first administration (acute, Day 1), and another set $1 \mathrm{~h}$ after the challenge dose (Challenge day). The same schedule was concomitantly carried out with cocaine $(30 \mathrm{mg} / \mathrm{kg}$ ) for comparison. Moreover, we sacrificed one set of rats 1 (Day 5) and $24 \mathrm{~h}$ (Day 6) after receiving the fifth dose of the assigned treatment in order to study how the DA uptake at these time points was affected. The results are depicted in Fig. 6.

The two-way ANOVA showed significant effects of drug treatment $\left(\mathrm{F}_{2,48}=95.00\right.$, $\mathrm{p}<0.0001)$ and time $\left(\mathrm{F}_{3,48}=74.85, \mathrm{p}<0.0001\right)$, as well as an interaction between these factors $\left(\mathrm{F}_{6,48}=24.84, \mathrm{p}<0.0001\right)$. The results and pot-hoc tests showed that there was an increase in DA uptake after the challenge in the striatum of rats which had received the repeated administration of MDPV and that this increase was higher than that produced by a single administration $(\mathrm{p}<0.05)$. As occurred with the acute dose, the effects of cocaine, although significant, were less than those of MDPV and, interestingly, the increase in DA uptake produced by the challenge with cocaine did not significantly differ from that of the acute dose (Day 1). 
$1 \mathrm{~h}$ after the fifth dose (Day 5), DA uptake was increased in the animals receiving drugs, The increases, however, were not as high as those induced by the first doses (Day 1). Moreover, $24 \mathrm{~h}$ after the fifth dose (Day 6), the uptake levels were significantly reduced in the case of MDPV-treated rats, whereas those treated with cocaine did not show significant differences with respect to saline.

\section{Comparative effects of MDPV and cocaine in hyperlocomotion and stereotyped behavior during the repeated administration procedure}

Locomotor activity of rats was measured during the five days of administration and the challenge day in order to assess whether locomotor sensitization had also occurred. A two-way ANOVA with repeated measures revealed significant effects of treatment $\left(\mathrm{F}_{2,15}\right.$ $=38.21, \mathrm{p}<0.0001)$ and day $\left(\mathrm{F}_{4,60}=4.17, \mathrm{p}<0.01\right)$, but no interaction between these variables. MDPV (1.5 mg/ $\mathrm{kg}$ ) and cocaine (30 mg/kg, which is considered a high dose) induced similar increases in locomotor activity (Fig. 7a). Interestingly, over the daily administration period, locomotor activity decreased in the case of MDPV or did not significantly change in the case of cocaine. Moreover, on the challenge day the two-way ANOVA revealed significant effects of treatment $\left(\mathrm{F}_{1,10}=17.79, \mathrm{P}<0.01\right)$ and day $\left(\mathrm{F}_{2,20}\right.$ $=27.49, \mathrm{p}<0.0001)$ as well as an interaction between the two variables $\left(\mathrm{F}_{2,20}=7.952\right.$ $\mathrm{p}<0.01)$. The locomotor activity induced by both drugs was significantly less than that induced on the first day (Fig. 7b).

However, we observed an increase in stereotypies over the administration days, including repetitive head weaving, sniffing and rearing, which could account for the reduction in ambulation. To explore this hypothesis, we re-analyzed the videos and scored the stereotyped behavior. The results are displayed in Figure 7 (Panels c and d), and the two-way ANOVA with repeated measures revealed a significant effect of treatment $\left(\mathrm{F}_{2,15}=74.40, \mathrm{p}<0.0001\right)$ and day $\left(\mathrm{F}_{4,60}=43,87, \mathrm{p}<0.0001\right)$ and a significant interaction between these factors $\left(\mathrm{F}_{8,60}=10.33, \mathrm{p}<0.0001\right)$. The stereotypy score increased along the five days of treatment (Fig. 7c) and there was a sensitization of the stereotyped behavior on the challenge day for both drugs ( $p<0.001$, Fig. 7d). Again, the stereotypy score on the challenge day for MDPV was higher than that of cocaine. The overall two-way repeated measures ANOVA comparing the stereotypies on Day 1 and after the challenge showed significant effects of treatment $\left(F_{2,15}=91.33, p<0.0001\right)$ and 
day $\left(\mathrm{F}_{1,15}=149.1, \mathrm{p}<0.0001\right)$, as well as an interaction between these factors $\left(\mathrm{F}_{2,15}=\right.$ 26.56, $\mathrm{p}<0.0001)$.

Finally, to assess whether the increase in stereotypies was correlated with the decreased locomotion, we carried out the correlation analysis between stereotypy score and distance (shown in Fig. 8). As can be observed, there was a very significant negative correlation between stereotypy score and distance in the case of MDPV, while the analysis corresponding to cocaine did not reach statistical significance.

\section{Discussion}

In the present work, we studied the regulatory effects of MDPV on DAT density and function in vitro as well as DAT function after an acute administration and during a repeated schedule, followed by drug removal. As cited in the Introduction, apart from the effects produced when they reach the synapses, psychostimulants can rapidly induce either up- or down-regulation of DAT depending on their mechanism of action. MDPV (like cocaine) is a non-substrate DAT blocker, (Baumann et al. 2013; Simmler et al. 2013), and therefore an up-regulation of this transporter would be expected. A small DA-releasing effect of MDPV at very low concentrations ( $1 \mathrm{nM})$ has also been reported (Shekar et al. 2017). However, the concentrations of MDPV reached in CNS after an average dosing are much higher (Novellas et al. 2015) and, therefore, a predominance of blockade is expected. Nevertheless, due to the higher affinity and potency on DAT when compared with cocaine, the study of such effects of MDPV are of great interest in order to increase the knowledge about this new drug and to predict possible side effects after its consumption.

To start with, we tested the effects of MDPV exposition on surface DAT density ( $\left[{ }^{3} \mathrm{H}\right]$ WIN 35428 binding) in NGF-differentiated PC 12 cells. This cell line develops a phenotype of dopaminergic neurons upon differentiation and, therefore, is a good model to study dopaminergic drugs and DAT (Greene and Tischler 1976; Kittner et al. 1987; Chipana et al. 2008). We must point out that binding was carried out on intact plateattached cells, in order to avoid binding to intracellular forms of DAT which would have masked any change in the membrane population. Using this experimental model, we found that MDPV, at a concentration within those achieved in brain and plasma after recreational administration (Novellas et al. 2015), produces a rapid up-regulation of $\left[{ }^{3} \mathrm{H}\right]$ WIN 35428 binding sites which persists for at least $3 \mathrm{~h}$. These results are in 
agreement with those reported by other groups using cell lines transfected with hDAT $24 \mathrm{~h}$ incubation might have several explanations that require further investigation. One possibility could be the spontaneous degradation of MDPV or cell metabolism as PC 12 have been reported to express several xenobiotic metabolizing cytochrome P450 isoforms (Kashyap et al. 2011). The decrease in MDPV concentration may lead to a process of restorarion of DAT levels.

Recently, Colon-Perez et al. (2018) reported a rapid internalization of fluorescencelabeled DAT after $1 \mathrm{~h}$ exposure to MDPV $(0.3 \mu \mathrm{M})$ in transfected HEK cells, whereas we found an increase in surface $\left[{ }^{3} \mathrm{H}\right]$ WIN 35428 binding. A possible explanation to this discrepancy is the fact that the model they used is not a neural derived cell line, does not constitutively express DAT, and does not contain dopamine or other monoamines. By contrast, PC 12 cells and striatal synaptosomes express DAT and might be equipped with all the machinery that may be involved in DAT trafficking and regulation in dopaminergic neurons under physiological conditions (i.e., secretory vesicles, dopamine receptors and dopamine itself) whereas the cell line used by Colon-Perez et al. might not. In fact, Little et al. (2002) used a neuronal cell line (N2A) for similar purposes and reported, as we do, an up-regulation of DAT upon incubation with cocaine, which is in line with our results and others'.

The next step was to investigate whether this binding up-regulation was accompanied by increased DA uptake. For this reason, we moved to the in vitro model of striatal synaptosomes. This model had been successfully used by our group and others for measuring the effects of an acute exposure to METH and MDMA (Chipana et al. 2006; Escubedo et al. 2005; Hansen et al. 2002; Pubill et al. 2005; Sandoval et al. 2001). In these experiments, we studied the kinetics of DA uptake in striatal synaptosomes treated with buffer, MDPV or cocaine at the same concentration for $1 \mathrm{~h}$. MDPV significantly increased $\mathrm{V}_{\max }$, as cocaine, and increased $\mathrm{K}_{\mathrm{M}}$, whereas cocaine did not significantly modify this parameter. The increase in $\mathrm{V}_{\max }$ is compatible with the increased $\left[{ }^{3} \mathrm{H}\right] \mathrm{WIN}$ 35428 binding we found in PC12 cells treated with MDPV and that reported in hDATtransfected cell lines treated with cocaine (Little et al. 2002; Zahniser and Sorkin 2009) and indicates that there exists a rapid functional up-regulation of DAT upon acute exposition to MDPV and cocaine. The fact that $\mathrm{K}_{\mathrm{M}}$ remained unchanged after treatment with cocaine is in agreement with the results from Little et al. (2002) using transfected 
cells. To our knowledge, this is the first time that such up-regulation is reported for MDPV and for cocaine in rat striatal synaptosomes. Moreover, the fact that these effects are produced in vitro in synaptosomes suggests that this up-regulation takes place rapidly, at the nerve terminals, without the need of increased gene translation or de novo protein synthesis. This is in line with the results reported using transfected cell lines, where no changes in DAT total protein or mRNA were found (Little et al. 2002; Zahniser and Sorkin 2009), suggesting a fast effect on DAT trafficking from endosomes to the plasma membrane by a mechanism that remains to be elucidated. The greater effects of MDPV compared with cocaine could be explained by its higher affinity for DAT (Baumann et al. 2013; Simmler et al. 2013).

The relevance and relative impact of both increased $\mathrm{K}_{\mathrm{M}}$ and $\mathrm{V}_{\max }$ for DA uptake in the case of MDPV deserves further investigation. An interesting point is that significant increases in these two parameters have been reported in the nucleus accumbens of postmortem brains from schizophrenic patients (Haberland and Hetey 1987). In fact, the reported increase in $\mathrm{K}_{M}$ was about two-fold, whereas what we found was about $50 \%$. The changes in DAT function could be responsible, at least in part, of the psychiatric effects observed in some MDPV abusers (Schmoll et al. 2017).

In addition, we assessed the effect of an in vitro incubation ( $1 \mathrm{~h})$ with increasing concentrations of MDPV and cocaine on DA uptake. At a substrate concentration of 0.2 $\mu \mathrm{M}, \mathrm{MDPV}$ significantly increased uptake only at $0.1 \mu \mathrm{M}$ while the concentrations of 0.05 and $1 \mu \mathrm{M}$ only reached statistical significance when compared with control using a Student's t-test (data not shown). Interestingly, the uptake values at concentrations of 1 $\mu \mathrm{M}$ and above were lower than at $0.1 \mu \mathrm{M}$, regardless increased $\mathrm{V}_{\max }$ was found thanks to using higher substrate concentrations. An explanation to this point could be the high affinity of MDPV for DAT, which is probably accompanied by a very slow dissociation rate. This slow dissociation makes necessary to perform repetitive washes to remove all drug residuals and reveal the transporter up-regulation. In fact, the MDPV concentrations of 10 and $50 \mu \mathrm{M}$ initially produced uptake down-regulation when performing three washes (not shown), whereas performing one additional wash resulted in an uptake value higher than $100 \%$. This phenomenon could also explain the increase in $\mathrm{K}_{\mathrm{M}}$ produced by MDPV, which suggests that, despite the up-regulation of transporters, a higher amount of substrate would be necessary to reach half the $V_{\max }$ because the function of part of the DAT population might be impaired by residual 
MDPV or previous exposition to high concentrations of drug. Conversely, the highest effect, which was lower than that of MDPV and in line with an increased $V_{\max }$ without changes in $\mathrm{K}_{\mathrm{M}}$.

Given the in vitro effects of MDPV, we further investigated whether an in vivo acute dose of this drug induced such up-regulation and compared its effects with those of cocaine. In this case, we used doses of both drugs that produced similar psychomotor effects and measured uptake at a single concentration of $\left[{ }^{3} \mathrm{H}\right] \mathrm{DA}$, which according to the previous kinetic experiments showed the highest difference between groups. The upregulation of DA uptake also appeared in drug-treated animals, and the percentages of increase were higher than those found in vitro $\left(\mathrm{V}_{\max }\right)$, indicating that the in vivo conditions facilitate the observed effects. Again, MDPV showed a higher potency than cocaine at up-regulating DA uptake. Moreover, its effects lasted at least $3 \mathrm{~h}$ postadministration, whereas the effects of cocaine were not significantly elevated at this time point. In both cases, the effect was reversible and no differences were found $16 \mathrm{~h}$ later. The longer persistence of MDPV effects could be explained by its long half-live in the brain, as significant levels of this drug can be found in striatum $3 \mathrm{~h}$ after administration (Novellas et al. 2015). Moreover, MDPV seems to have a slower dissociation from DAT, which implies the need to perform several washes of the preparation to remove residual drug, which can still be detected by HPLC-MS in synaptosomes even after tissue homogenization and centrifugation (data not shown). On the other hand, cocaine has been reported to disappear more rapidly from the brain, so that its concentration in rat brain is very low at $1 \mathrm{~h}$ after administration (Bowman et al. 1999). This could explain why its effects on DAT are less persistent after a single administration. An aspect to consider is how long DAT is up-regulated once the drug concentration has declined in brain, because an increased number of DAT in the absence of blocker could produce a hypodopaminergic status that may lead to search for drug re-dosing.

The next experiments focused on DA uptake after a repeated administration of these psychostimulants. Mash et al. (2002) reported a parallel increase in $\mathrm{B}_{\max }$ of $\left[{ }^{3} \mathrm{H}\right] \mathrm{WIN}$ 35428 binding and $\mathrm{V}_{\max }$ for $\left[{ }^{3} \mathrm{H}\right] \mathrm{DA}$ uptake in post-mortem synaptosomes from cocaine abusers, indicating functional upregulation of DAT following chronic cocaine use. Another group (Samuvel et al. 2008) described that rats which self-administered cocaine 
followed by a 3-week abstinence showed a higher level of surface DAT and DA uptake

No previous reports exist concerning the effects of MDPV on DAT density and function, so we investigated the function of DAT after a repeated administration regime with MDPV or cocaine, followed by a period of withdrawal and a challenge with the drug. Interestingly, we found a sensitization of the DA uptake up-regulation induced by MDPV, but not by cocaine. This indicates that MDPV, at the dose used, affects the population of DAT or its trafficking mechanisms differently, leading to increased upregulation by a re-exposure to the drug after a period of withdrawal. Further investigations are warranted in order to determine what mechanisms are involved in such effect. In line with these findings, when we assessed DA uptake $24 \mathrm{~h}$ after the fifth daily dose, we observed that uptake levels of cocaine-treated rats did not differ from controls, whereas those of the MDPV-treated group were significantly lower. This finding evidences again the differences between MDPV and cocaine. A recent publication by Colon-Perez et al. (2018) also reports DAT down-regulation $24 \mathrm{~h}$ after the administration of MDPV to rats. Moreover, we had previously reported a decrease in $\left[{ }^{3} \mathrm{H}\right]$ WIN 35428 binding in the striatum of mice that had received a repeated administration of MDPV (1.5 mg/kg) for 7 days after 21 days of withdrawal (preliminary results presented as a communication at the Neuroscience 2017 congress by Duart-Castells et al.). Although in the present work we did not measure DAT function after withdrawal, just before the challenge, these previous results suggest that DAT would be still down-regulated at this time point (10 days after). A reduced DAT population would also explain, at least in part, why the challenge with the same dose of MDPV increases the stereotypies, as the blockade of DA uptake would be higher, leading to a hyperdopaminergic status. Consequently, a higher uptake up-regulation would be expected as an attempt to restore normal DA synaptic levels.

DAT down-regulation may be a homeostatic response once MDPV disappeared from the brain and left an increased population of free transporters that would dramatically reduce DA in the synapses if it was not normalized. The fact that DA uptake levels have returned to control values $16 \mathrm{~h}$ after an acute administration backs this argument. Moreover, $1 \mathrm{~h}$ after the fifth dose, DA uptake was significantly increased but to a lesser extent with respect to the first dose in MDPV rats, and closer to controls in the cocaine group. This suggests the development of a tolerance to the up-regulation of DAT that 
may reflect a reduction in rapidly available DAT after the repeated administration. This could also account in some extent, to the subsequent reduction in DAT and to the sensitization of the homeostatic mechanism to respond to further exposures to the drug. Another interesting issue was the behavioral responses to this repeated administration regime. Behavioral sensitization to psychostimulants can be attributed not only to a direct pharmacological action of the drug but also to environmental conditions associated with the drug experience (Pierce and Kalivas 1997). It has been suggested that behavioral sensitization could be involved in the development and maintenance of drug addiction (Tzschentke and Schmidt 2000) through enhanced incentive salience (Robinson and Berridge 1993). When we measured locomotor activity every day after the drug administration we observed a progressive decrease in the locomotor response to the drug in the case of MDPV and a non-significant change in the case of cocaine. This response was also reflected on the challenge day, when both drug-treated groups showed a reduced locomotor activity after the drug administration when compared to that induced by the first dose, and very significant in the case of MDPV. These behaviors, however, were correlated with an increase in stereotypies, especially in the case of MDPV. Stereotypies appear after administration of a number of psychotropic drugs and become more apparent at higher doses in the case of psychostimulants, to an extent that they can preclude hyperlocomotion and mask it when measured as an indicator of psychostimulation (Creese and Iversen 1974; Pritchard et al. 2012). It has been suggested that stereotyped behavior is correlated with an imbalance between the medial prefrontal and sensorimotor circuits of the basal ganglia resulting in a loss of control of motor behavior (Aliane et al. 2009). Given the higher potency of MDPV, relatively low doses (if compared with cocaine) are able to produce stereotypies in rats and sensitization to these effects (Gregg et al. 2016). Similar effects had already been described for cocaine (Aliane et al. 2009; Souza et al. 2014). Our results are in line with those reported by Watterson et al. (2016), who used a 5-day daily or every $48 \mathrm{~h}$ administration of MDPV ( 1 or $5 \mathrm{mg} / \mathrm{kg}$ ) followed by 5 days of withdrawal to assess motor sensitization. With this schedule, they only found motor sensitization to MDPV in the case of administering the drug every $48 \mathrm{~h}$ and at the dose of $1 \mathrm{mg} / \mathrm{kg}$ and attributed the lack of effect of $5 \mathrm{mg} / \mathrm{kg}$ to the strong stereotyped behavior that this dose induces, although they did not quantify stereotypies. In our case and theirs using the 
daily administration of $1 \mathrm{mg} / \mathrm{kg}$, sensitization to stereotypies might have developed more easily, thus precluding the locomotor sensitization.

A reduced population of DAT at the time of challenge could account for an increased psychostimulant effect of MDPV leading to more intense stereotypies. Thus, the increased up-regulation of DAT with respect to Day 1 could obey an attempt to reduce the excess of DA in the synapses after the intense blockade by MDPV.

In summary, we demonstrate here that acute exposure to MDPV induces rapid and reversible up-regulation of DAT function, probably as a response to the intense blockade exerted by the drug. This effect takes place at the nerve terminal, without the need of gene transcription or de novo protein synthesis, and is higher than that exerted by an equimolar (in vitro) or an equipotent (in vivo) dose of cocaine. Moreover, after repeated administration of MDPV, sensitization occurs to this effect. Further studies are needed to assess the impact of this regulation in the addictive properties of this drug, as well as to investigate the molecular mechanisms involved. 


\section{Figure captions}

Fig. 1 Effect of MDPV $(0.1 \mu \mathrm{M})$ during different incubation times on $\left[{ }^{3} \mathrm{H}\right]$ WIN 35428 binding to intact differentiated PC12 cells. Results are the means of two independent experiments carried out in triplicates and are expressed as the mean \pm SEM of the percentage from the binding obtained in medium-treated cells (control). ${ }^{*} \mathrm{p}<0.01$; $* * * \mathrm{p}<0.001$ vs. control

Fig. 2 Effect of pre-incubation with MDPV $(1 \mu \mathrm{M})$ on $\left[{ }^{3} \mathrm{H}\right] \mathrm{DA}$ uptake kinetics in rat striatal synaptosomes Panel a shows the values of $V_{\max }$, while panel $b$ shows those of $\mathrm{K}_{\mathrm{M}}$. Results are the means \pm SEM from five experiments carried out on duplicates. Panel c depicts a representative experiment of such kinetics. $* * p<0.01$ vs. control Fig. 3 Effect of pre-incubation with cocaine $(1 \mu \mathrm{M})$ on $\left[{ }^{3} \mathrm{H}\right] \mathrm{DA}$ uptake kinetics in rat striatal synaptosomes. Panel a shows the values of $V_{\max }$, while panel $b$ shows those of $\mathrm{K}_{\mathrm{M}}$. Results are the means \pm SEM from five experiments carried out on duplicates. Panel $\mathrm{c}$ depicts a representative experiment of such kinetics. ${ }^{*} \mathrm{p}<0.05$ vs. control Fig. 4 Effect of increasing MDPV (a) and cocaine (b) concentrations on [ $\left.{ }^{3} \mathrm{H}\right] \mathrm{DA}$ uptake in rat striatal synaptosomes. Results are the means \pm SEM from four experiments carried out on duplicates. ${ }^{*} \mathrm{p}<0.05 ;{ }^{*} \mathrm{p}<0.01$ vs. control $(0 \mu \mathrm{M})$

Fig. $5\left[{ }^{3} \mathrm{H}\right] \mathrm{DA}$ uptake in striatal synaptosomes from rats treated acutely with saline (1 $\mathrm{ml} / \mathrm{kg}$, s.c.), MDPV (1.5 mg/kg, s.c.) or cocaine (30 mg/kg, i.p.) and sacrificed after 1,3 or 16 hours. Uptake values are normalized as percentage of control (saline group, 100 $\%)$ and are the means \pm SEM of those from four animals per group and time. ANOVA post-hoc comparisons: ${ }^{* * *} \mathrm{p}<0.001$ vs. saline at the same time point; ${ }^{\# \#} \mathrm{p}<0.001$ vs. cocaine at the same time point

Fig. 6 Effects of repeated daily administration of MDPV or cocaine on striatal DA uptake at different time points. Results are expressed as percentage of control (saline group, $100 \%$ ) and are the mean \pm SEM ( $n=4-6$ per group). Tukey's post-hoc test: $* * * \mathrm{p}<0.001, * * \mathrm{p}<0.01$ vs. saline at the same time point; ${ }^{\# \#} \mathrm{p}<0.001,{ }^{\# \#} \mathrm{p}<0.01$ vs. cocaine at the same time point; ${ }^{\$ \$} \mathrm{p}<0.001,{ }^{\$} \mathrm{p}<0.05$ with respect to the same treatment group at Day $1 ;{ }^{@} @ \mathrm{p}<0.001$ with respect to the same treatment group at Day 5

Fig. 7 a. Locomotor activity during daily administration of saline $(1 \mathrm{ml} / \mathrm{kg}), \operatorname{MDPV}(1.5$ $\mathrm{mg} / \mathrm{kg}$, s.c.) or cocaine (30 mg/kg, i.p.) to rats for 5 consecutive days. b. Locomotor 
activity induced by a challenge with saline ( $1 \mathrm{ml} / \mathrm{kg}$, s.c.), MDPV $(1.5 \mathrm{mg} / \mathrm{kg}$, s.c.) or cocaine $(30 \mathrm{mg} / \mathrm{kg}$, i.p.) after 10 days of withdrawal, compared with the distance recorded on Day 1. Panels c and d show the stereotypy scores assigned from the corresponding recordings to the data depicted in A and $\mathrm{B}$, respectively. Data represent the mean \pm SEM of the values from 6 rats per group. ${ }^{*} \mathrm{p}<0.05, * * \mathrm{p}<0.01, * * * \mathrm{p}<0.001$ $v s$. the corresponding value on Day $1 .{ }^{\#} \mathrm{p}<0.05$ between the indicated groups

Fig. 8 Correlation analyses between the means of the stereotypy score and the corresponding travelled distance during the consecutive 5 days of treatment with saline (1 ml/kg), MDPV (1.5 mg/kg, s.c.) or cocaine (30 mg/kg, i.p.) 


\section{Reference list}

Aarde SM, Huang PK, Creehan KM, et al (2013) The novel recreational drug 3,4methylenedioxypyrovalerone (MDPV) is a potent psychomotor stimulant: Selfadministration and locomotor activity in rats. Neuropharmacology 71:130-140. doi: 10.1016/j.neuropharm.2013.04.003

Aliane V, Pérez S, Nieoullon A, et al (2009) Cocaine-induced stereotypy is linked to an imbalance between the medial prefrontal and sensorimotor circuits of the basal ganglia. Eur J Neurosci 30:1269-1279. doi: 10.1111/j.1460-9568.2009.06907.x

Alvarez J-C, Fabresse N, Larabi IA (2018) Prevalence and Surveillance of Synthetic Cathinones Use by Hair Analysis: An Update Review. Curr Pharm Des 23:5487-5495. doi: $10.2174 / 1381612823666170704124156$

Bade R, Bijlsma L, Sancho J V., et al (2017) Liquid chromatography-tandem mass spectrometry determination of synthetic cathinones and phenethylamines in influent wastewater of eight European cities. Chemosphere 168:1032-1041. doi:

10.1016/j.chemosphere.2016.10.107

Baumann MH, Partilla JS, Lehner KR, et al (2013) Powerful Cocaine-Like Actions of 3,4-Methylenedioxypyrovalerone (MDPV), a Principal Constituent of Psychoactive 'Bath Salts' Products. Neuropsychopharmacology 38:552-562. doi: 10.1038/npp.2012.204

Bowman BP, Vaughan SR, Walker QD, et al (1999) Effects of sex and gonadectomy on cocaine metabolism in the rat. J Pharmacol Exp Ther 290:1316-1323

Buenrostro-Jáuregui M, Ciudad-Roberts A, Moreno J, et al (2016) Changes in CREB and deltaFosB are associated with the behavioural sensitization induced by methylenedioxypyrovalerone. J Psychopharmacol. 30:707-712. doi:

$10.1177 / 0269881116645300$

Cameron K, Kolanos R, Verkariya R, et al (2013) Mephedrone and methylenedioxypyrovalerone (MDPV), major constituents of "bath salts," produce opposite effects at the human dopamine transporter. Psychopharmacology (Berl) 227:493-499. doi: 10.1007/s00213-013-2967-2 
Cervinski MA, Foster JD, Vaughan RA (2005) Psychoactive substrates stimulate dopamine transporter phosphorylation and down-regulation by cocaine-sensitive and protein kinase C-dependent mechanisms. J Biol Chem 280:40442-9. doi:

\subsection{4/jbc.M501969200}

Chipana C, Camarasa J, Pubill D, Escubedo E (2006) Protection against MDMAinduced dopaminergic neurotoxicity in mice by methyllycaconitine: involvement of nicotinic receptors. Neuropharmacology 51:885-95. doi:

10.1016/j.neuropharm.2006.05.032

Chipana C, García-Ratés S, Camarasa J, et al (2008) Different oxidative profile and nicotinic receptor interaction of amphetamine and 3,4-methylenedioxymethamphetamine. Neurochem Int 52:401-410. doi: 10.1016/j.neuint.2007.07.016

Colon-Perez LM, Pino JA, Saha K, et al (2018) Functional connectivity, behavioral and dopaminergic alterations 24 hours following acute exposure to synthetic bath salt drug methylenedioxypyrovalerone. Neuropharmacology 137:178-193. doi:

10.1016/j.neuropharm.2018.04.031

Creese I, Iversen SD (1974) The role of forebrain dopamine systems in amphetamine induced stereotyped behavior in the rat. Psychopharmacologia 39:345-357

Daws LC, Callaghan PD, Morón JA, et al (2002) Cocaine increases dopamine uptake and cell surface expression of dopamine transporters. Biochem Biophys Res Commun. 290:1545-50. doi: 10.1006/bbrc.2002.6384

Escubedo E, Chipana C, Pérez-Sánchez M, et al (2005) Methyllycaconitine prevents methamphetamine-induced effects in mouse striatum: involvement of alpha7 nicotinic receptors. J Pharmacol Exp Ther 315:658-67. doi: 10.1124/jpet.105.089748

Farfel GM, Kleven MS, Woolverton WL, et al (1992) Effects of repeated injections of cocaine on catecholamine receptor binding sites, dopamine transporter binding sites and behavior in rhesus monkey. Brain Res 578:235-43

Fleckenstein AE, Metzger RR, Wilkins DG, et al (1997) Rapid and reversible effects of methamphetamine on dopamine transporters. J Pharmacol Exp Ther 282:834-8 
Gatch MB, Taylor CM, Forster MJ (2013) Locomotor stimulant and discriminative stimulus effects of "bath salt" cathinones. Behav Pharmacol 24:437-47. doi:

10.1097/FBP.0b013e328364166d

Giambalvo CT (2003) Differential effects of amphetamine transport vs. dopamine reverse transport on particulate PKC activity in striatal synaptoneurosomes. Synapse 49:125-33. doi: 10.1002/syn.10223

Greene LA, Tischler AS (1976) Establishment of a noradrenergic clonal line of rat adrenal pheochromocytoma cells which respond to nerve growth factor. Proc Natl Acad Sci USA 73:2424-2428

Gregg RA, Tallarida CS, Reitz AB, Rawls SM (2013) Mephedrone interactions with cocaine: prior exposure to the 'bath salt' constituent enhances cocaine-induced locomotor activation in rats. Behav Pharmacol 24:684-688. doi:

10.1097/FBP.0000000000000006

Gregg RA, Hicks C, Nayak SU, et al (2016) Synthetic cathinone MDPV downregulates glutamate transporter subtype I (GLT-1) and produces rewarding and locomotoractivating effects that are reduced by a GLT-1 activator. Neuropharmacology 108:111119. doi: 10.1016/j.neuropharm.2016.04.014

Haberland N, Hetey L (1987) Studies in postmortem dopamine uptake. II. Alterations of the synaptosomal catecholamine uptake in postmortem brain regions in schizophrenia. $\mathbf{J}$ Neural Transm 68:303-313

Hansen JP, Riddle EL, Sandoval V, et al (2002) Methylenedioxymethamphetamine decreases plasmalemmal and vesicular dopamine transport: mechanisms and implications for neurotoxicity. J Pharmacol Exp Ther 300:1093-100

Haughey HM, Brown JM, Wilkins DG, et al (2000) Differential effects of methamphetamine on $\mathrm{Na}(+) / \mathrm{Cl}(-)$-dependent transporters. Brain Res 863:59-65

Izenwasser S, Cox BM (1990) Daily cocaine treatment produces a persistent reduction of $[3 \mathrm{H}]$ dopamine uptake in vitro in rat nucleus accumbens but not in striatum. Brain Res $531: 338-41$ 
Johnson LA, Furman CA, Zhang M, et al (2005) Rapid delivery of the dopamine transporter to the plasmalemmal membrane upon amphetamine stimulation.

Neuropharmacology 49:750-758. doi: 10.1016/j.neuropharm.2005.08.018

Johnson PS, Johnson MW (2014) Investigation "bath salts" use patterns within an online sample of users in the United States. J Psychoactive Drugs 46:369-78. doi: $10.1080 / 02791072.2014 .962717$

Kashyap MP, Singh AK, Kumar V, Tripathi VK, et al (2011) Monocrotophos induced apoptosis in PC12 cells: role of xenobiotic metabolizing cytochrome P450s. PLoS One. 6:e17757. doi: 10.1371/journal.pone.0017757.

Kesha K, Boggs CL, Ripple MG, et al (2013) Methylenedioxypyrovalerone ("bath salts"), related death: case report and review of the literature. J Forensic Sci 58:1654-9. doi: $10.1111 / 1556-4029.12202$

Kittner B, Bräutigam M, Herken H (1987) PC12 cells: a model system for studying drug effects on dopamine synthesis and release. Arch Int Pharmacodyn Ther 286:18194

Kolanos R, Solis E, Sakloth F, et al (2013) “Deconstruction” of the Abused Synthetic Cathinone Methylenedioxypyrovalerone (MDPV) and an Examination of Effects at the Human Dopamine Transporter. ACS Chem Neurosci 4:1524-1529. doi: $10.1021 / \mathrm{cn} 4001236$

Letchworth SR, Daunais JB, Hedgecock AA, Porrino LJ (1997) Effects of chronic cocaine administration on dopamine transporter mRNA and protein in the rat. Brain Res 750:214-22

Little KY, Zhang L, Desmond T, et al (1999) Striatal dopaminergic abnormalities in human cocaine users. Am J Psychiatry 156:238-45. doi: 10.1176/ajp.156.2.238

Little KY, Elmer LW, Zhong H, et al (2002) Cocaine induction of dopamine transporter trafficking to the plasma membrane. Mol Pharmacol 61:436-45

Loder MK, Melikian HE (2003) The dopamine transporter constitutively internalizes and recycles in a protein kinase C-regulated manner in stably transfected PC12 cell lines. J Biol Chem 278:22168-74. doi: 10.1074/jbc.M301845200 
Lohr KM, Masoud ST, Salahpour A, Miller GW (2017) Membrane transporters as mediators of synaptic dopamine dynamics: implications for disease. Eur J Neurosci 45:20-33. doi: 10.1111/ejn.13357

López-Arnau R, Luján MA, Duart-Castells L, et al (2017) Exposure of adolescent mice to 3,4-methylenedioxypyrovalerone increases the psychostimulant, rewarding and reinforcing effects of cocaine in adulthood. Br J Pharmacol 174:1161-1173. doi: 10.1111/bph.13771

Mash DC, Pablo J, Ouyang Q, et al (2002) Dopamine transport function is elevated in cocaine users. J Neurochem 81:292-300

Metzger RR, Haughey HM, Wilkins DG, et al (2000) Methamphetamine-induced rapid decrease in dopamine transporter function: role of dopamine and hyperthermia. $\mathrm{J}$ Pharmacol Exp Ther 295:1077-85

Novellas J, López-Arnau R, Carbó ML, et al (2015) Concentrations of MDPV in rat striatum correlate with the psychostimulant effect. J Psychopharmacol 29:1209-1918. doi: $10.1177 / 0269881115598415$

Peraile I, Torres E, Mayado A, et al (2010) Dopamine transporter down-regulation following repeated cocaine: implications for 3,4-methylenedioxymethamphetamineinduced acute effects and long-term neurotoxicity in mice. Br J Pharmacol 159:201-11. doi: 10.1111/j.1476-5381.2009.00522.x

Pierce RC, Kalivas PW (1997) A circuitry model of the expression of behavioral sensitization to amphetamine-like psychostimulants. Brain Res Brain Res Rev 25:192216

Pritchard LM, Hensleigh E, Lynch S (2012) Altered locomotor and stereotyped responses to acute methamphetamine in adolescent, maternally separated rats. Psychopharmacology (Berl) 223:27-35. doi: 10.1007/s00213-012-2679-z

Pubill D, Chipana C, Camins A, et al (2005) Free radical production induced by methamphetamine in rat striatal synaptosomes. Toxicol Appl Pharmacol 204:57-68. doi: 10.1016/j.taap.2004.08.008 
Ramamoorthy S, Shippenberg TS, Jayanthi LD (2011) Regulation of monoamine transporters: Role of transporter phosphorylation. Pharmacol Ther 129:220-238. doi: 10.1016/j.pharmthera.2010.09.009

Reagan-Shaw S, Nihal M, Ahmad N (2008) Dose translation from animal to human studies revisited. FASEB J 22:659-661. doi: 10.1096/fj.07-9574LSF

Ritz MC, Lamb RJ, Goldberg SR, Kuhar MJ (1987) Cocaine receptors on dopamine transporters are related to self-administration of cocaine. Science 237:1219-23

Robinson TE, Berridge KC The neural basis of drug craving: an incentive-sensitization theory of addiction. Brain Res Brain Res Rev 18:247-291

Samuvel DJ, Jayanthi LD, Manohar S, et al (2008) Dysregulation of dopamine transporter trafficking and function after abstinence from cocaine self-administration in rats: evidence for differential regulation in caudate putamen and nucleus accumbens. $\mathbf{J}$ Pharmacol Exp Ther 325:293-301. doi: 10.1124/jpet.107.130534

Sandoval V, Riddle EL, Ugarte Y V, et al (2001) Methamphetamine-induced rapid and reversible changes in dopamine transporter function: an in vitro model. J Neurosci 21:1413-9

Saunders C, Ferrer J V, Shi L, et al (2000) Amphetamine-induced loss of human dopamine transporter activity: an internalization-dependent and cocaine-sensitive mechanism. Proc Natl Acad Sci USA 97:6850-5. doi: 10.1073/pnas.110035297 Schmitt KC, Reith MEA (2010) Regulation of the dopamine transporter: Aspects relevant to psychostimulant drugs of abuse. Ann N Y Acad Sci 1187:316-340. doi: 10.1111/j.1749-6632.2009.05148.x

Schmoll S, Romanek K, Stich R, et al (2017) An internet-based survey of 96 Germanspeaking users of "bath salts": frequent complications, risky sexual behavior, violence, and delinquency. Clin Toxicol 56:219-222. doi: 10.1080/15563650.2017.1353094

Shekar A, Aguilar JI, Galli G, et al (2017) Atypical dopamine efflux caused by 3,4methylenedioxypyrovalerone (MDPV) via the human dopamine transporter. J Chem Neuroanat 83-84:69-74. doi: 10.1016/j.jchemneu.2017.01.004 
Simmler L, Buser T, Donzelli M, et al (2013) Pharmacological characterization of 5381.2012.02145.x

Souza MF, Couto-Pereira NS, Freese L, et al (2014) Behavioral effects of endogenous or exogenous estradiol and progesterone on cocaine sensitization in female rats. Brazilian J Med Biol Res = Rev Bras Pesqui medicas e Biol 47:505-14

Staley JK, Hearn WL, Ruttenber AJ, et al (1994) High affinity cocaine recognition sites on the dopamine transporter are elevated in fatal cocaine overdose victims. J Pharmacol Exp Ther 271:1678-85

Sulzer D, Galli A (2003) Dopamine transport currents are promoted from curiosity to physiology. Trends Neurosci 26:173-6. doi: 10.1016/S0166-2236(03)00063-8

Torres GE, Gainetdinov RR, Caron MG (2003) Plasma membrane monoamine transporters: structure, regulation and function. Nat Rev Neurosci 4:13-25. doi: $10.1038 / \mathrm{nrn} 1008$

Tzschentke TM, Schmidt WJ (2000) Differential effects of discrete subarea-specific lesions of the rat medial prefrontal cortex on amphetamine- and cocaine-induced behavioural sensitization. Cereb Cortex 10:488-498

Watterson LR, Kufahl PR, Taylor SB, Nemirovsky NE, Olive MF (2016) Sensitization to the motor stimulant effects of 3,4-methylenedioxypyrovalerone (MDPV) and crosssensitization to methamphetamine in rats. J Drug Alcohol Res pii: 235967. doi: $10.4303 /$ jdar/235967.

Wilson JM, Kish SJ (1996) The vesicular monoamine transporter, in contrast to the dopamine transporter, is not altered by chronic cocaine self-administration in the rat. J Neurosci 16:3507-10

Wright TH, Cline-Parhamovich K, Lajoie D, et al (2013) Deaths involving methylenedioxypyrovalerone (MDPV) in Upper East Tennessee. J Forensic Sci 58:1558-62. doi: 10.1111/1556-4029.12260

Zahniser NR, Sorkin A (2009) Trafficking of dopamine transporters in psychostimulant actions. Semin Cell Dev Biol 20:411-417. doi: 10.1016/j.semcdb.2009.01.004 
Zuba D, Byrska B (2013) Prevalence and co-existence of active components of 'legal highs.' Drug Test Anal 5:420-429. doi: 10.1002/dta.1365 


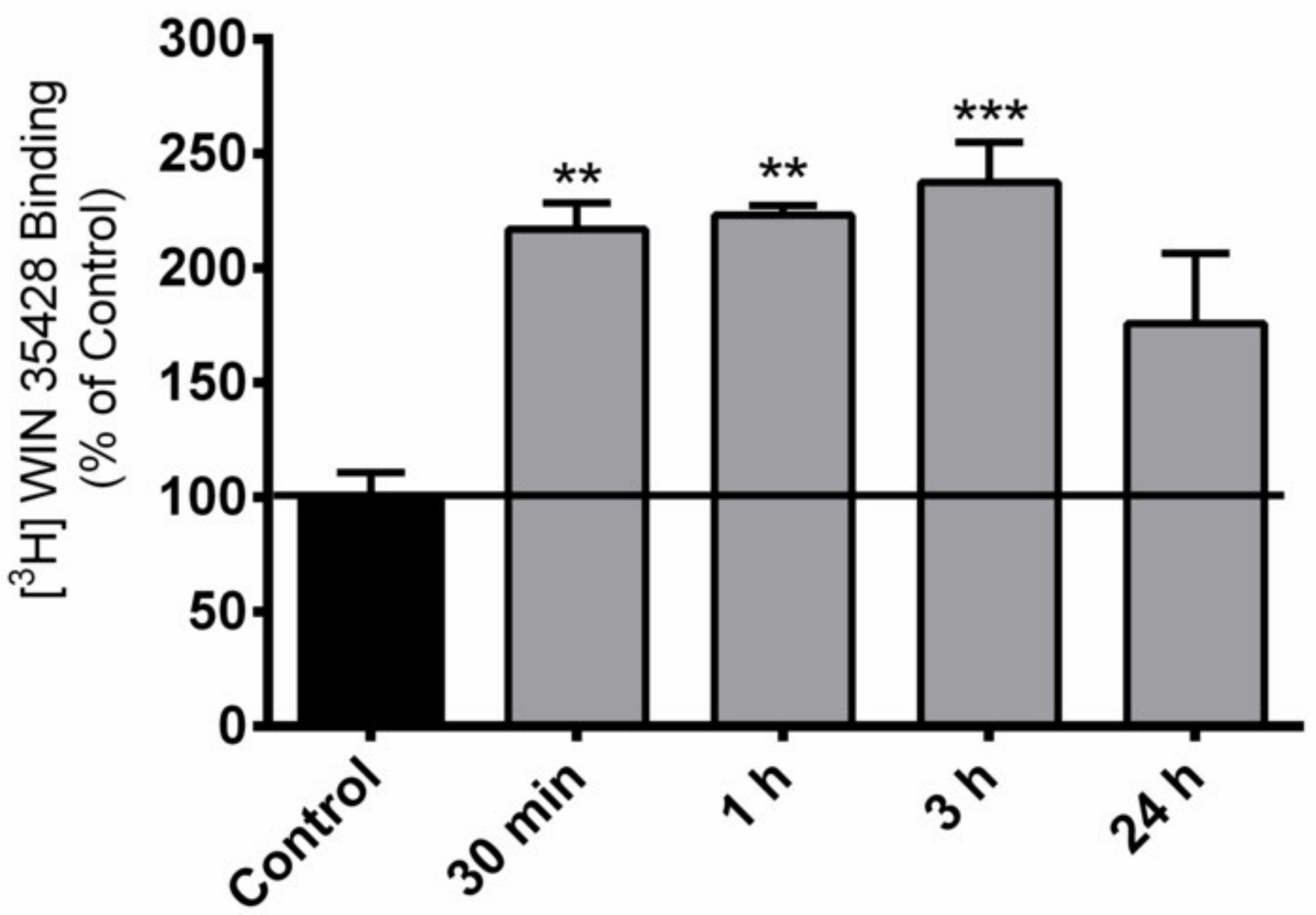


a

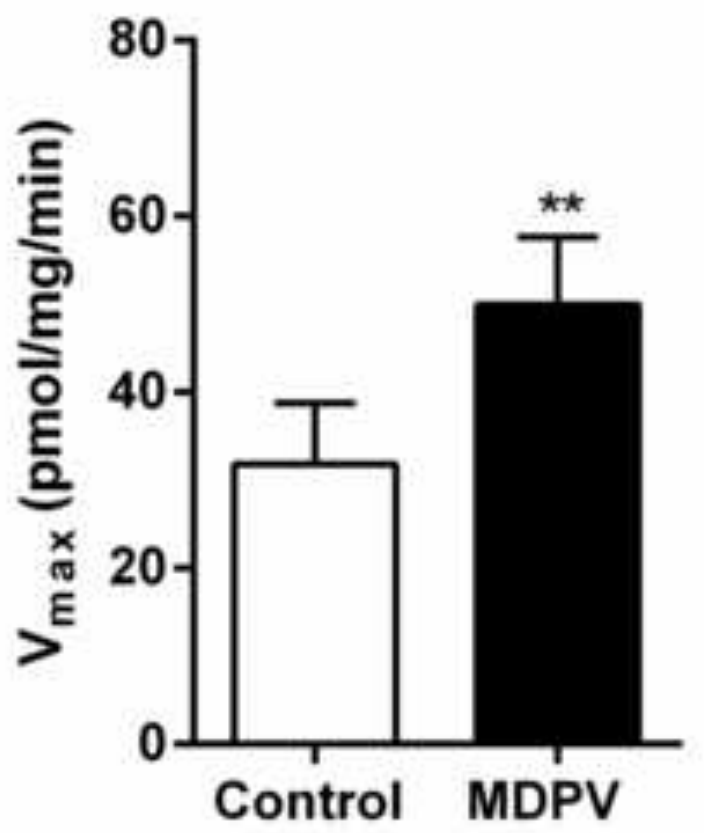

b
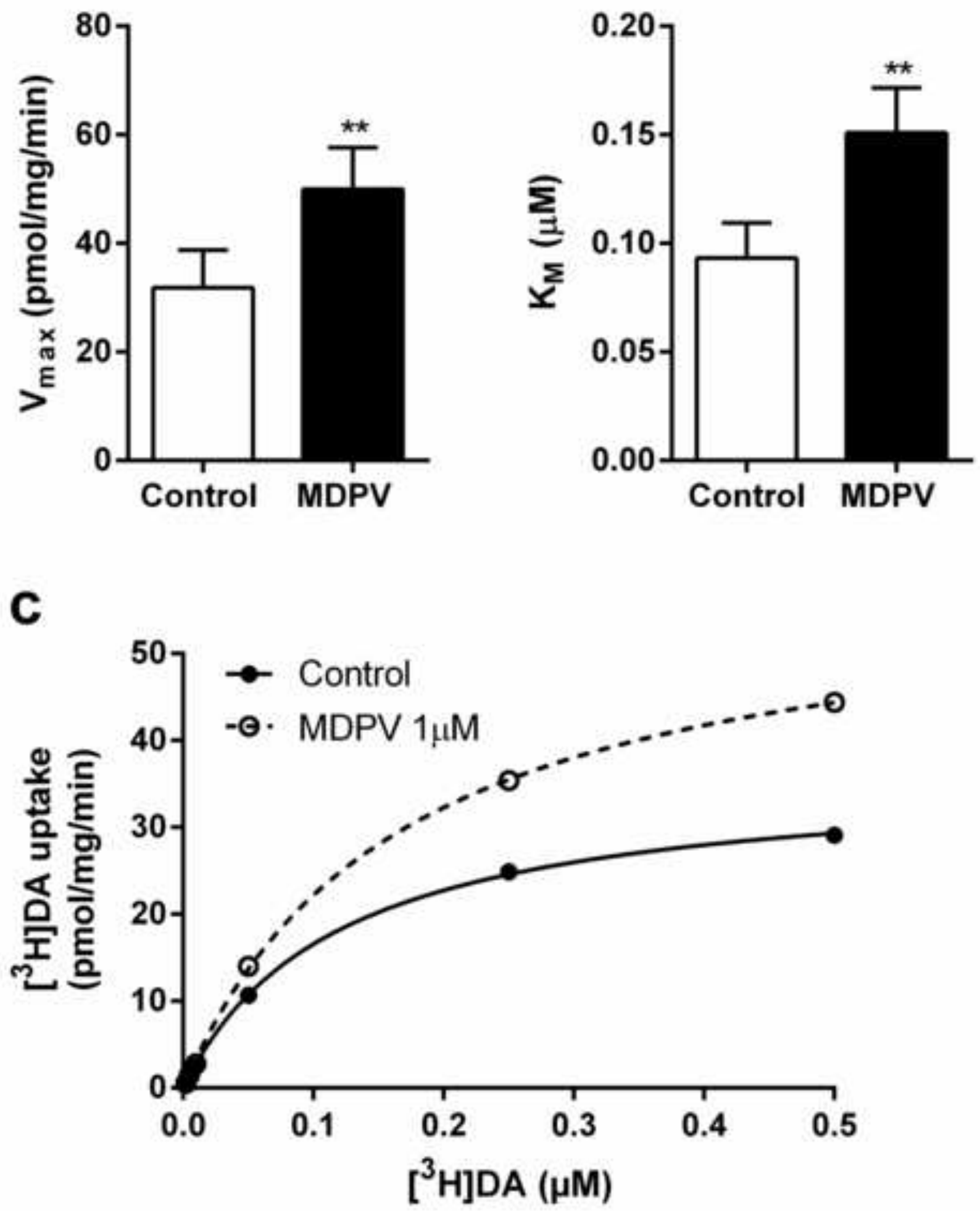
a

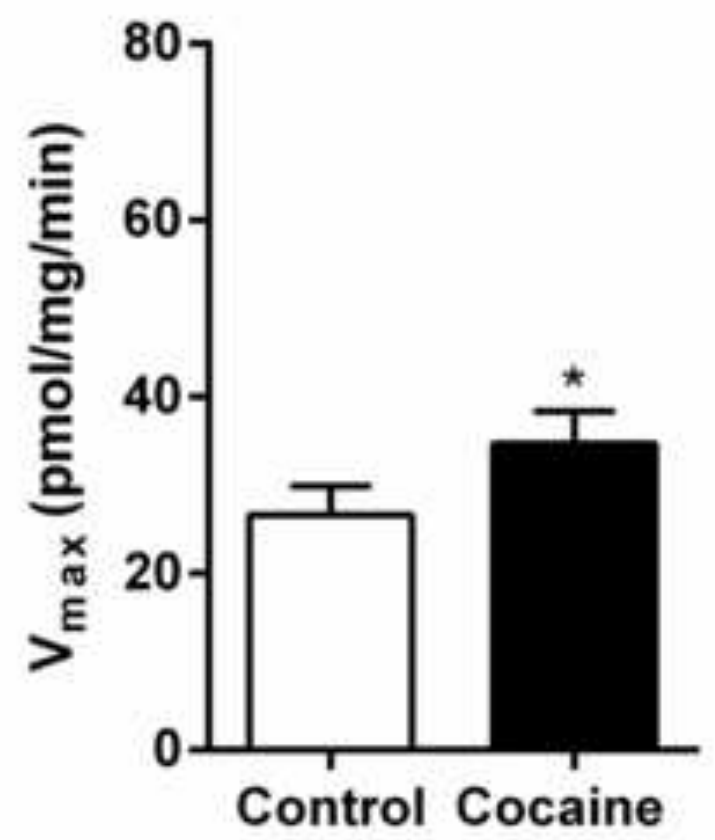

b

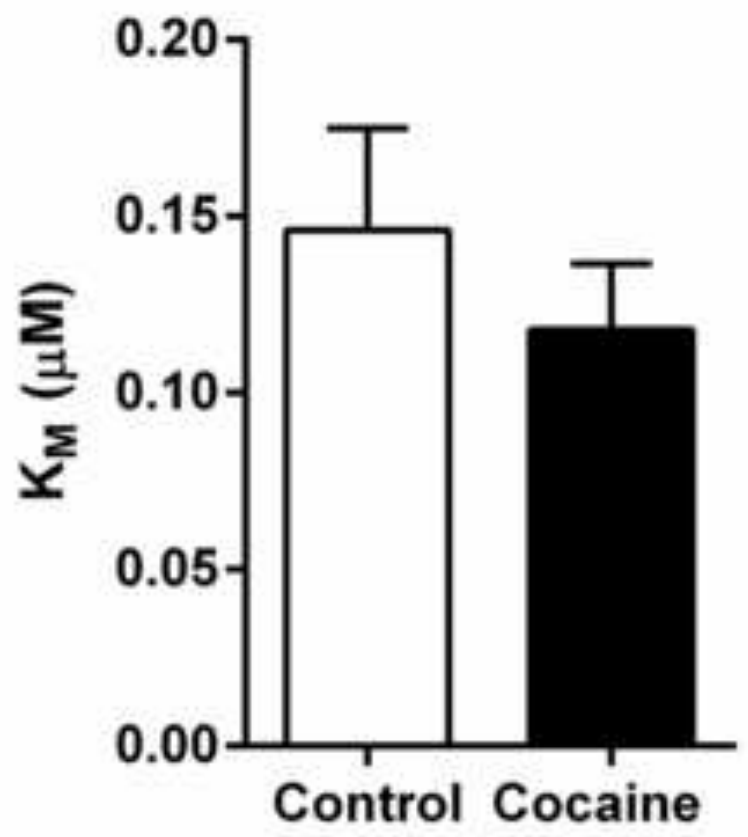

C

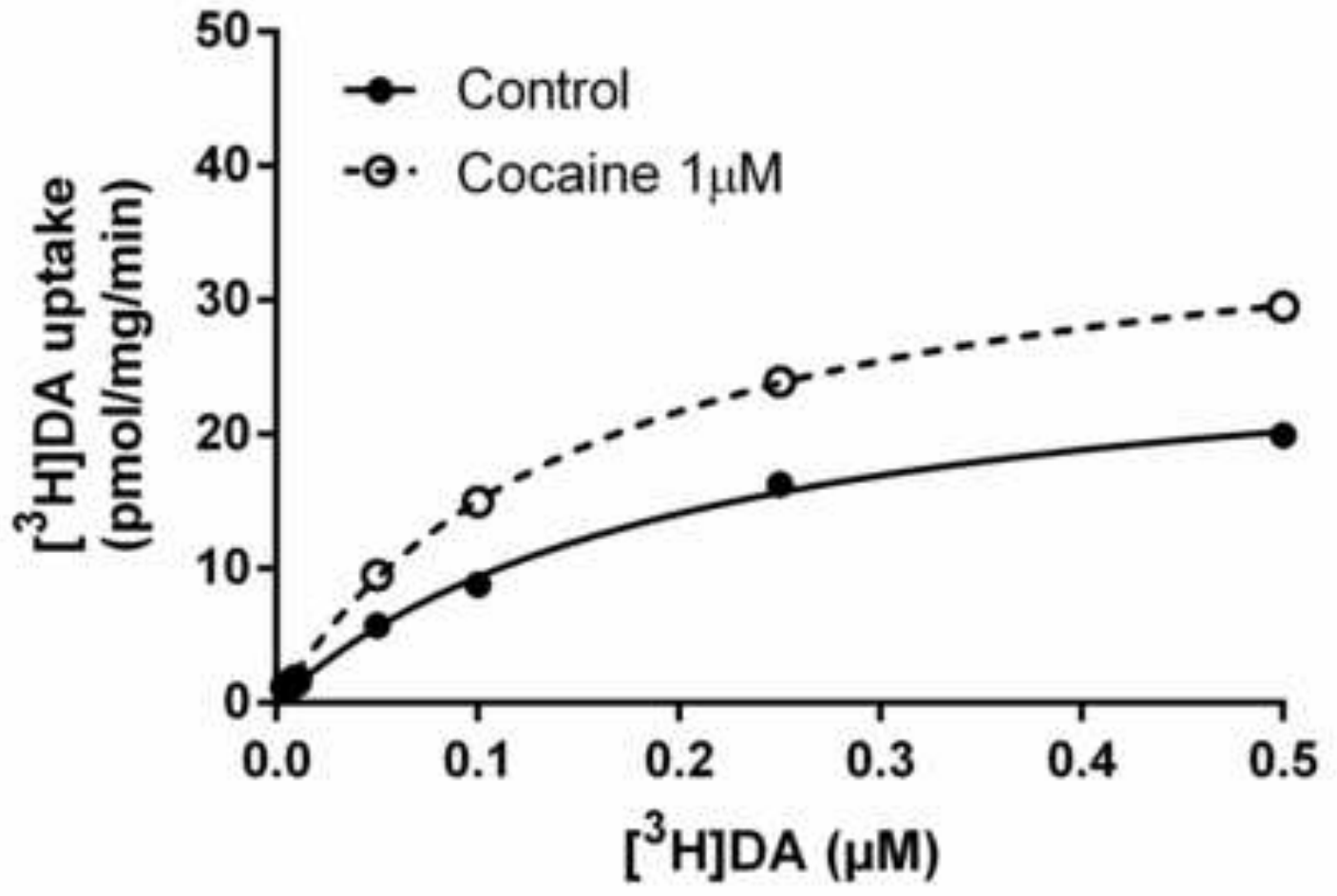


a

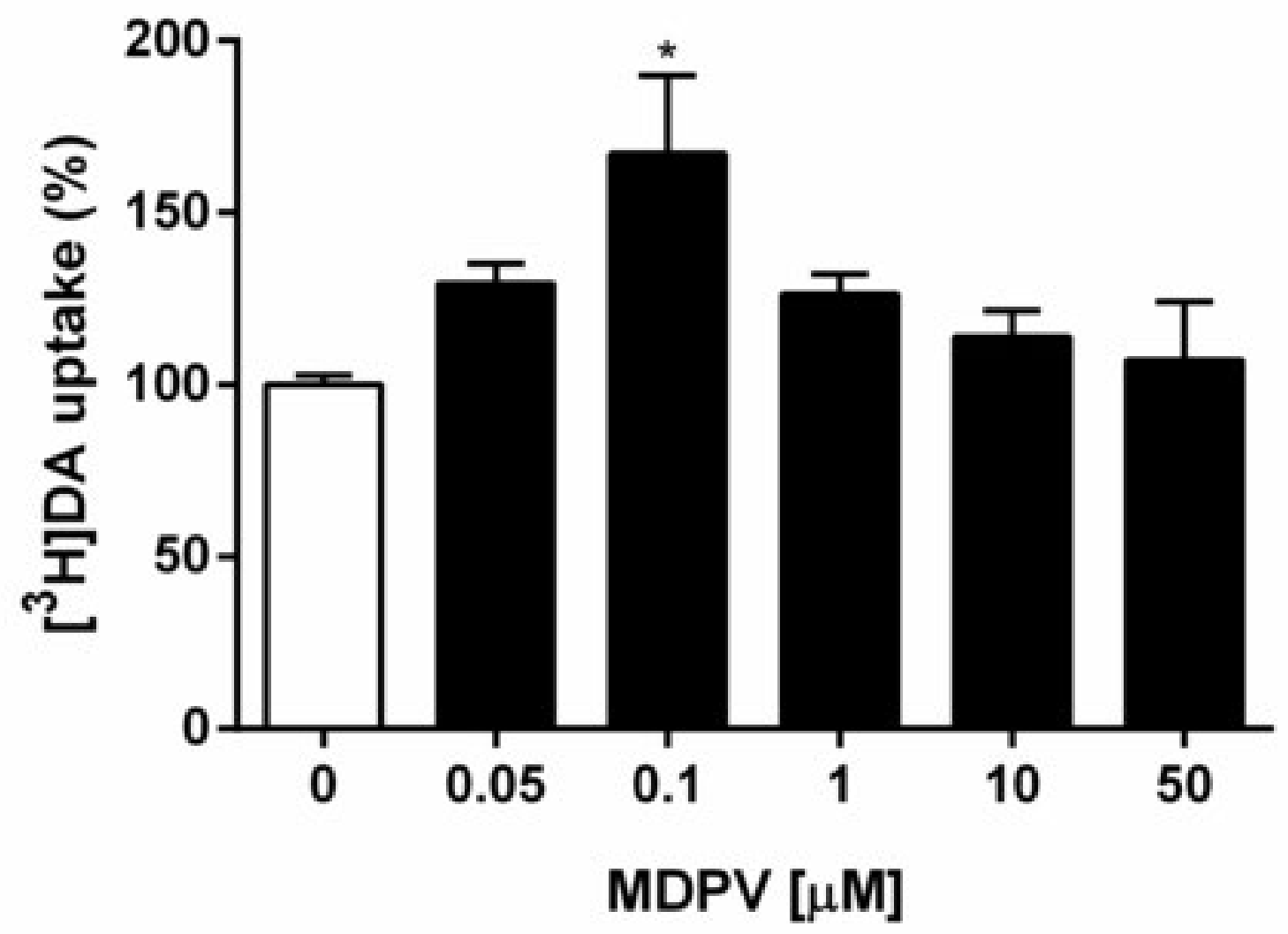

b

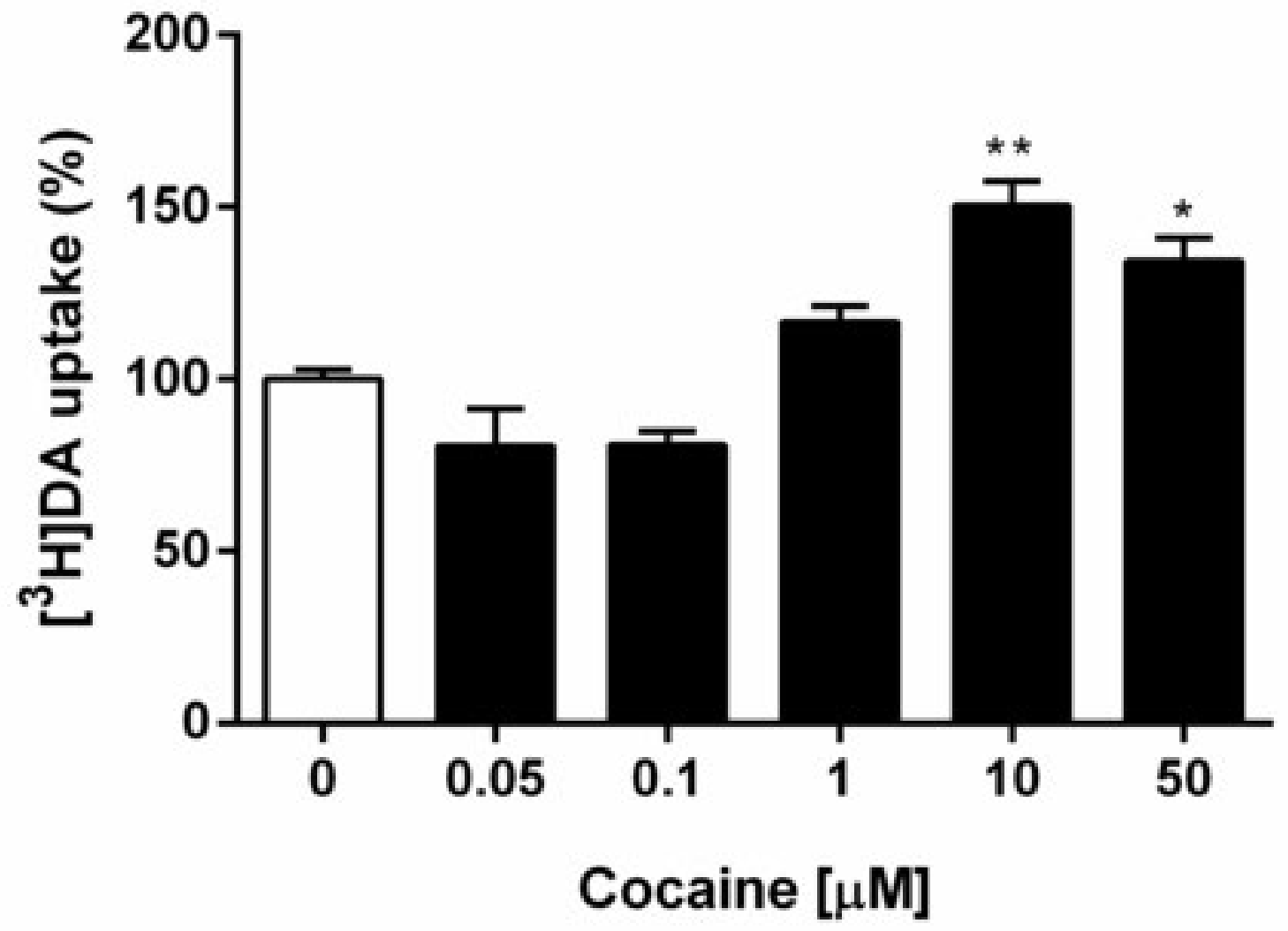




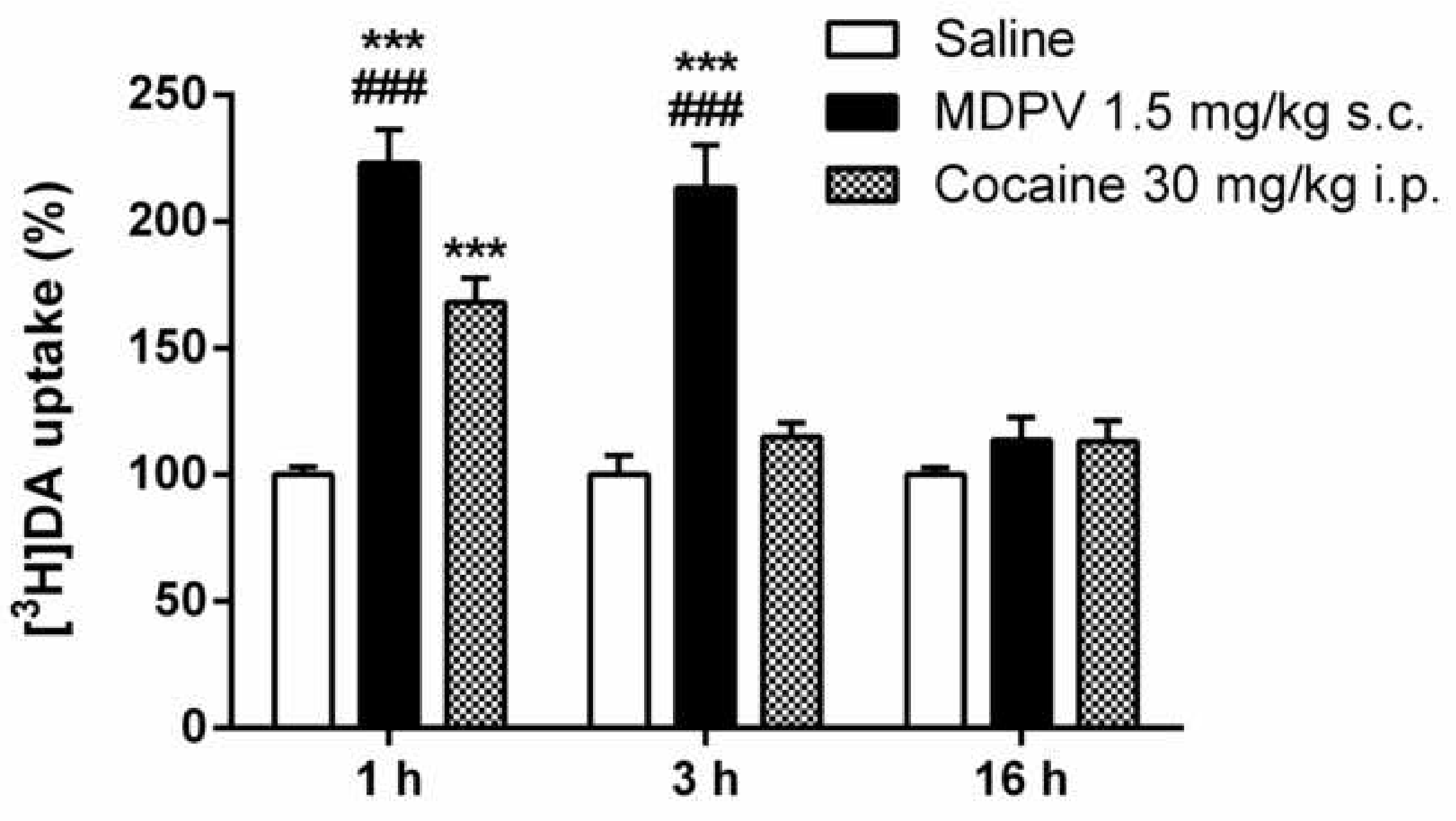

Time after administration 


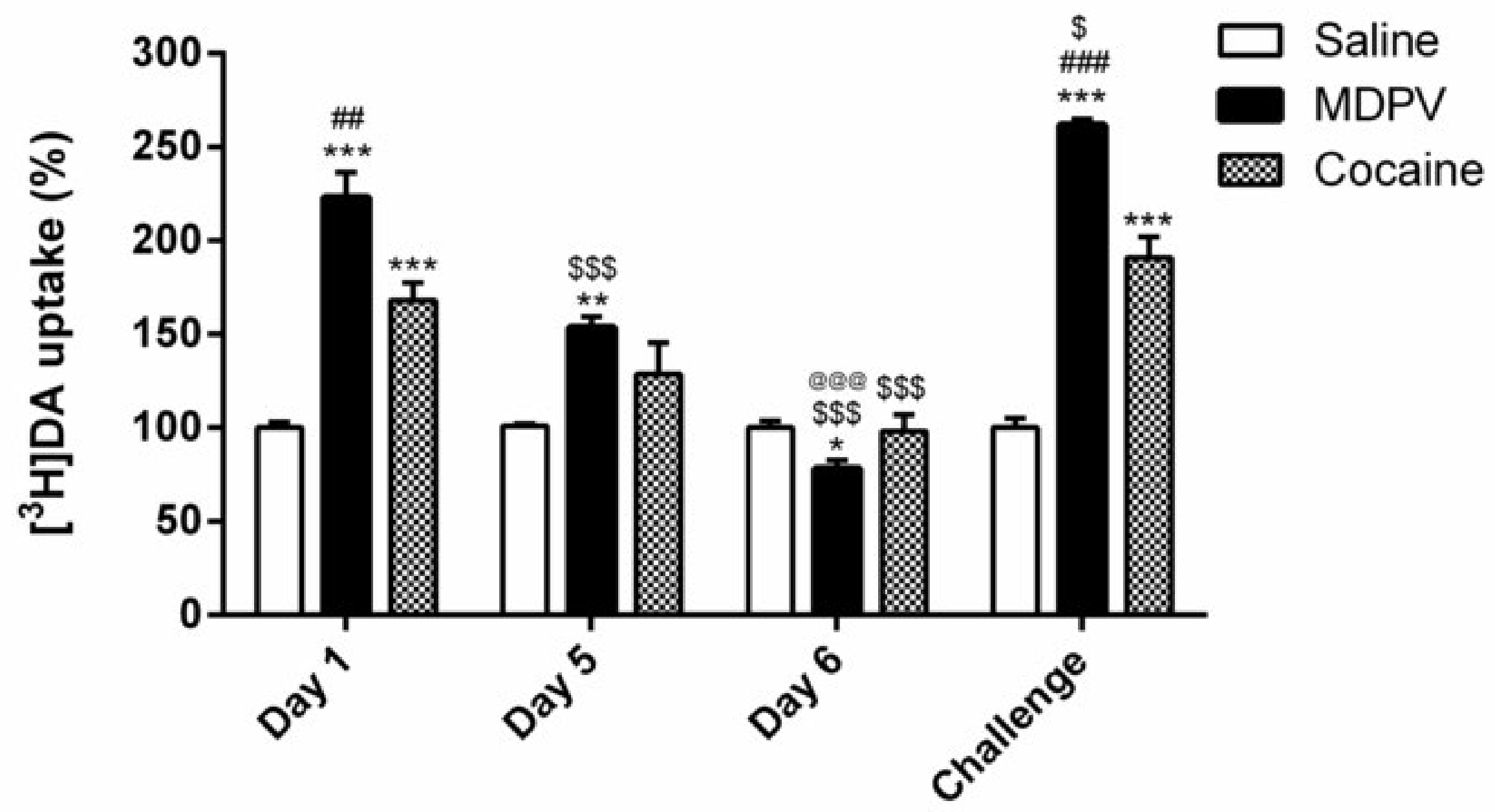



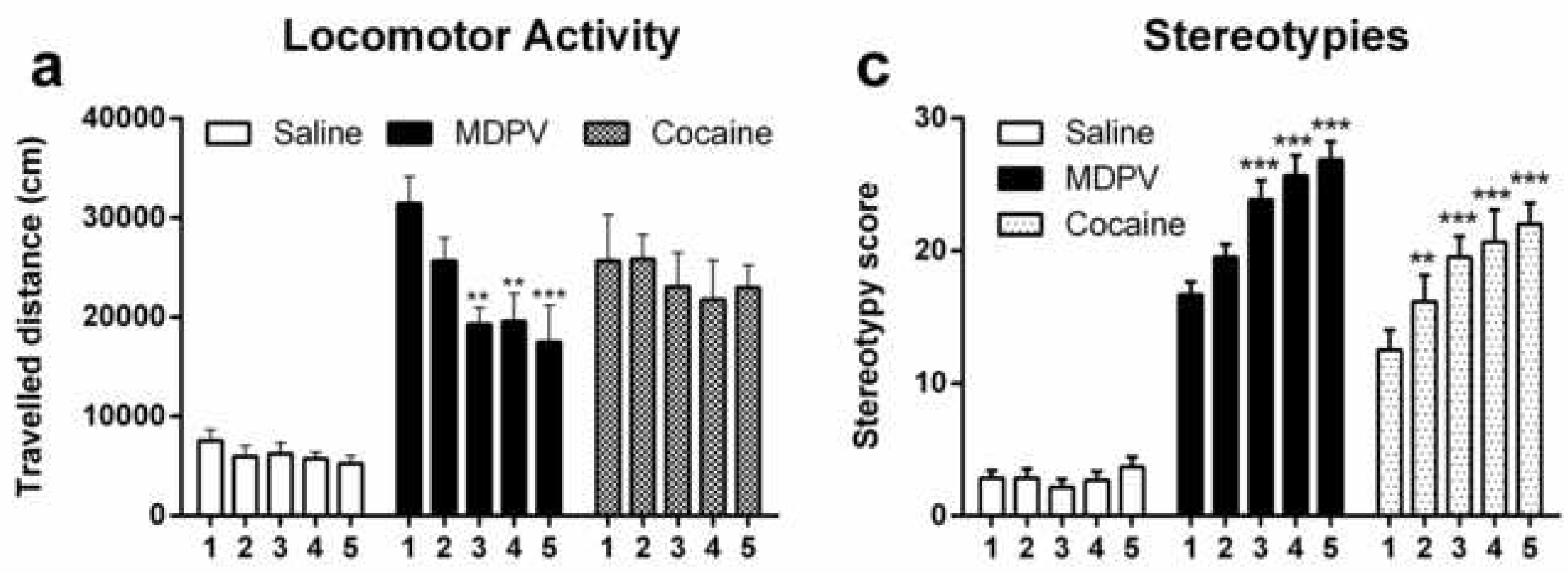

Day
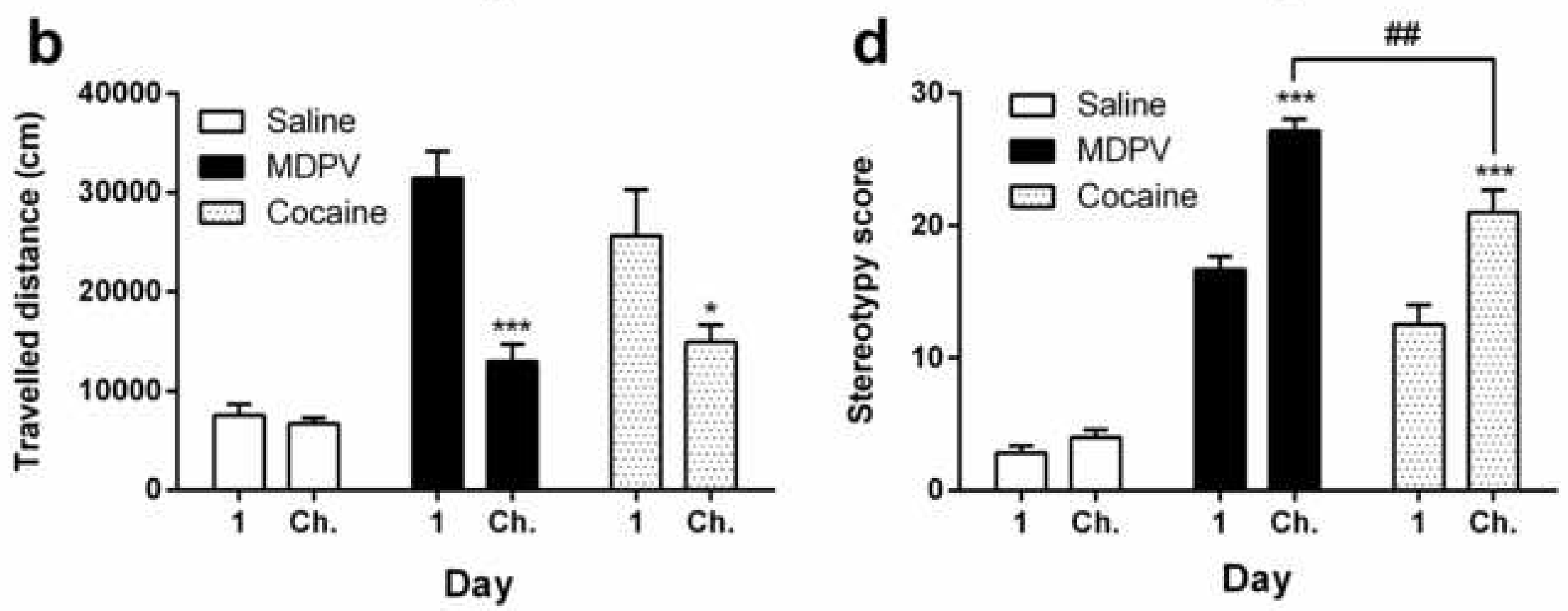


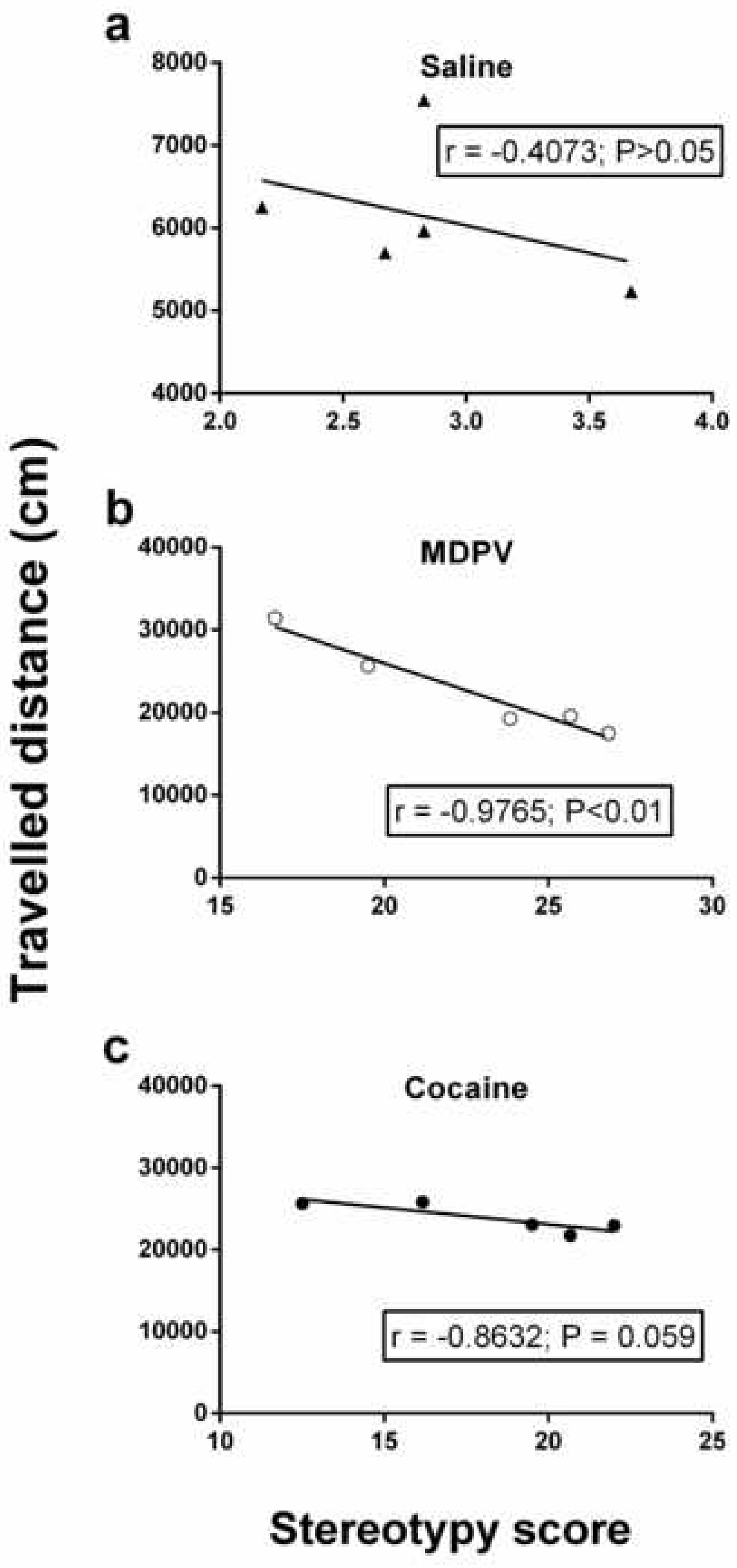

